\title{
Innovar modelos de gestión para mejorar la calidad de los doctorados en educación en Colombia ${ }^{1}$
}

\author{
Innovating management models to improve the doctoral education quality in \\ Colombia
}

\author{
Gilma Rosa Sanabria León
}

\begin{abstract}
Resumen
La investigación que da origen a este artículo se orientó a comprender los factores de calidad y las prácticas de gestión presentes en los Programas de Formación Doctoral en Educación en Colombia, centrada en el caso específico de un programa doctoral de la Ciudad de Bogotá. Se visibilizan preocupantes indicadores que reflejan deficiencias en los factores y características de calidad, tanto en lo relacionado a la organización, gestión e impacto social del conocimiento, como en los objetivos misionales del programa académico. Se evidencia además una baja producción académica y de investigación, y la que existe presenta un mediano impacto teórico, metodológico y social. Un Programa Doctoral en Educación endogámico, con poco diálogo e interacción con programas similares a nivel regional, nacional e internacional, presentando un escaso trabajo colaborativo, en red y de conexiones que estimulen el debate de saberes necesario en este alto nivel de formación. Se identificaron también, sin embargo, fortalezas destacables vistas desde los indicadores nacionales e internacionales, a pesar de que las políticas nacionales e institucionales no apoyan en forma decidida ni estimulan los programas de investigación en educación. Así, este artículo plantea la necesidad de dar un salto a nuevos modelos de gestión educativa a partir del análisis de un caso concreto, desde la certeza de que la evaluación constituye el primer paso para redimensionar la organización del trabajo conjunto hacia la construcción de un sistema que permita mejorar la calidad de los doctorados en educación en Colombia.
\end{abstract}

\section{Palabras clave}

Calidad, Educación, Doctorado, Programas de Doctorado, Gestión.

\begin{abstract}
The research underlying this article was aimed at understanding the quality factors and the management practices present in Doctoral Training Programs in Education in Colombia, focusing on the specific case of a doctoral program in the city of Bogotá. Become visible worrying indicators that reflect deficiencies in the quality factors and features, related to the organization, management and social impact of knowledge, as in the missionary objectives of the curriculum. A low academic and research output, and a medium theoretical, methodological and social impact of the production were also showed. Is a endogamous Doctoral Program in Education, with a low dialogue and interaction with similar programs regionally, nationally and internationally. It present too a little collaborative work, networking and connections that stimulate discussion of knowledge needed in this high level of training. Were also identified, however, notable strengths views from national and international indicators, despite
\end{abstract}

1 Doctora en Educación UNED, Madrid, España. Docente e investigadora Universitaria. Coordinadora de Procesos de Acreditación. Jefe de la Oficina de Planeación Universitaria. Autora de libros, capítulos de libros y textos universitarios. Asesora y consultora para la creación de Programas Universitarios. Email: gilma_65@yahoo.com. 
national and institutional policies decisively not support or encourage research programs in education. Thus, this article suggests the need to leap to new models of educational management from the analysis of a case, from the certainty that the evaluation is the first step to resize the organization of the together working toward building a system that will improve the quality of doctoral education in Colombia.

\section{Key words}

Quality, Education, Ph.D., Doctoral Programs, Management.

\section{INTRODUCCIÓN}

El doctorado es la formación universitaria de más alto nivel, por ello su calidad es materia de constante preocupación. En una sociedad que se aprecia como fragmentada e inequitativa, la educación tiene hoy un gran desafío y los doctorados en educación que existen en Colombia no están respondiendo a las problemáticas relevantes de los diferentes niveles educativos del país.

El sistema educativo en Colombia está atravesando una transición importante en todos los niveles y por esto requiere la integración de los diversos sectores de la sociedad para pensar la educación desde necesidades y problemáticas propias. Silvia Gvirtz aporta un punto de vista interesante al respecto cuando afirma que es indispensable romper paradigmas en cuanto a los modelos de gestión para poder integrar los nuevos estilos de liderazgo que requieren las instituciones de educación en este momento histórico (Gvirtz y Podestá, 2007, p. 4).

En este escenario, la calidad en la educación se convierte en punto central del debate, pues ésta eleva el nivel de progreso de un país, contribuye a su desarrollo productivo y humano, es esencial para mejorar las condiciones de vida y para construir ciudadanía. En este ámbito el Estado, por su parte, debe formular políticas y acciones encaminadas a garantizar principios fundamentales como eficiencia, eficacia, pertinencia y equidad en pro de la calidad de la educación, en tanto ésta es un derecho fundamental.

No se puede perder de vista la calidad de la educación en los programas posgraduales, específicamente doctorados, ya que éstos tienen por objetivo la formación de investigadores con capacidad de realizar y orientar de forma autónoma procesos académicos e investigativos en un área específica de un campo de conocimiento; por tanto, la planeación diseño y desarrollo de programas académicos para este nivel de formación deben ser de alta rigurosidad. 
De acuerdo con el Consejo Nacional de Acreditación, CNA (2008), "En los últimos diez años, Colombia se ha quedado rezagada en la formación a nivel doctoral. Mientras en Colombia se están formando alrededor de 100 doctores por año, el nivel de formación anual en Chile es de 500, en México es de más de 1.000 y en Brasil de más de 11.000". Esto sin hablar de la distancia con los países desarrollados que es aún mayor. La problemática es clara, Según Andrés Openhaimmer (2011) "Latinoamérica es la región del mundo con menos inversión en investigación y desarrollo de nuevos productos, y con menos patentes registradas en el mercado mundial [...] sólo el 2 por ciento de la inversión mundial en investigación y desarrollo tiene lugar en los países latinoamericanos y caribeños. Comparativamente, 28 por ciento de la inversión mundial en este rubro tiene lugar en los países asiáticos, 30 por ciento en Europa, y 39 por ciento en Estados Unidos".

Teniendo en cuenta la importancia de los programas de doctorado en el "desarrollo científico-tecnológico y socio-económico" de los pueblos, en Colombia se está planeando una política de fomento al desarrollo de los posgrados con especial énfasis en los doctorados, lo que significa un crecimiento significativo en los próximos diez años. Ello alarma y reclama un urgente incremento del recurso humano especializado, pero sobre todo el aseguramiento de que los programas ofertados sean de alta calidad. Según el documento del CNA Lineamientos para la creación de alta calidad de Programas de Maestrías y Doctorados (2009): "Para poder lograr el desarrollo y la consolidación de maestrías y doctorados que puedan contribuir al desarrollo del país, es indispensable asegurar niveles de excelencia académica en los programas que se desarrollen".

Sin embargo, al hacer referencia a la calidad en educación, es necesario tener en cuenta las políticas del Estado, pero además revisar las políticas misionales de las Instituciones de Educación Superior, pues es claro que son los equipos directivos quienes crean las condiciones para que sea posible generar procesos de calidad para cumplir con las funciones sustantivas de la Educación Superior (Docencia, Investigación y Extensión).

Por esta razón se ha definido el eje de la gestión como generador del conjunto de acciones necesarias para alcanzar las metas educativas propuestas. En palabras de Ernesto Gore "se hace necesario interpretar la gestión como gesta generadora de nueva vida, incluir la diferencia para excluir la desigualdad y recuperar el poder de enseñar" 
(2004, p. 69). Se habla entonces de gestión como una oportunidad de proponer y organizar nuevas posibilidades, dinámicas e ideas que permitan reivindicar la función y el compromiso de la educación a nivel regional y global.

La investigación desarrollada se orientó a comprender los factores de calidad y las prácticas de gestión presentes en los Programas de Formación Doctoral en Educación en Colombia, centrada en el caso específico de un programa doctoral de la Ciudad de Bogotá. Se visibilizan preocupantes indicadores que reflejan deficiencias en los factores y características de calidad, tanto en lo relacionado a la organización, gestión e impacto social del conocimiento, como en los objetivos misionales del programa académico, sin dejar de lado que, de igual forma, se identificaron fortalezas destacables vistas desde los indicadores nacionales e internacionales, a pesar de que las políticas nacionales e institucionales no apoyan en forma decidida ni estimulan los programas de investigación en educación. Esto resulta contradictorio en relación con la reflexión de Openhaimmer (2011), para quien "la economía es un presupuesto, necesario, pero no sirve si no está acompañada de una educación de calidad. Es un error creer que todos los problemas de la sociedad se resuelven con crecimiento económico: el crecimiento no resuelve la pobreza, la pobreza la resuelve la educación" (p. 59).

En el estudio se pudo establecer una oferta académica en nivel doctoral en educación con una irregular calidad, con un débil arbitraje, baja evaluación externa y escaso número de doctorandos vinculados a los Grupos de Investigación Institucionales. Se evidencia además una baja producción académica y de investigación, y la que existe presenta un mediano impacto teórico, metodológico y social. Un Programa Doctoral en Educación endogámico, con poco diálogo e interacción con programas similares a nivel regional, nacional e internacional, presentando un escaso trabajo colaborativo, en red y de conexiones que estimulen el debate de saberes necesario en este alto nivel de formación. De igual manera, teniendo en cuenta lo estándares nacionales e internacionales de medición de calidad, se encontró un bajo equilibrio en la relación entre el número de docentes vinculados al programa y el número de estudiantes matriculados; incidiendo en una moderada calidad de la formación doctoral.

Así, este artículo plantea la necesidad de dar un salto a nuevos modelos de gestión educativa a partir del análisis de un caso concreto, desde la certeza de que la evaluación 
constituye el primer paso para redimensionar la organización del trabajo conjunto hacia la construcción de un sistema que permita mejorar la calidad de los doctorados en educación en Colombia.

\section{DISCUSIÓN TEÓRICA}

Solo partiendo del análisis de los contextos educativos pueden identificarse las problemáticas que están frenando la transformación de la educación en Colombia y por ende su calidad, e implementando planes de mejora acordes a las verdaderas necesidades de tales contextos.

Mejorar es un concepto que requiere partir de lo existente para reconstruirlo, por esta razón el ejercicio de evaluación de los procesos de calidad que hacen parte de la gestión educativa de la UPN resulta imprescindible, ya que como institución líder en procesos educativos en el país, también debería ser líder en un proceso de gestión educativa estratégica que integre y determine los aspectos que hacen que la educación sea de calidad.

La UNESCO define calidad en la educación superior como un concepto multidimensional, que se relaciona con elementos contextuales, fines institucionales y estándares específicos dentro de un sistema, institución, programa o disciplina determinados. "El objetivo último de la gestión debería ser el cumplimiento óptimo de la misión institucional asegurando una enseñanza, formación e investigación de gran calidad, y prestando servicios a la comunidad. Este objetivo requiere una dirección que combine la visión social, incluida la comprensión de los problemas mundiales, con competencias de gestión eficaces" (UNESCO, 2000).

Las prácticas de gestión para la enseñanza superior deberían adoptar una perspectiva de futuro que responda a las necesidades de sus entornos. El Instituto Internacional de Planeamiento de la Educación (IIPE) de la UNESCO define la gestión educativa como un saber de síntesis capaz de ligar conocimiento y acción, ética y eficacia, política y administración, en procesos que tienden al mejoramiento continuo de las prácticas 
educativas, a la exploración y explotación de todas las posibilidades y a la innovación permanente como proceso sistemático (UNESCO, 2000).

La gestión se caracteriza por una visión amplia de las posibilidades reales de una organización para resolver alguna situación o alcanzar un fin determinado. Se define como el conjunto de acciones integradas para el logro de un objetivo a cierto plazo; es la acción principal de la administración y es un eslabón intermedio entre la planificación y los objetivos concretos que se pretenden alcanzar.

Mintzberg y Stoner asumen el término gestión como la disposición y organización de los recursos de un individuo o grupo para obtener los resultados esperados. Pudiera generalizarse como el arte de anticipar participativamente el cambio, con el propósito de crear permanentemente estrategias que permitan garantizar el futuro deseado de una organización; es una forma de alinear esfuerzos y recursos para alcanzar un fin determinado (1995, p. 781).

Borja, plantea que la gestión es un conjunto de acciones que se llevan a cabo para alcanzar un objetivo previsto; planificación, implementación y el proceso de control y evaluación (2003).

El proceso de gestión directiva posibilita que los demás procesos se den y que la Institución construya buenas relaciones desde un proyecto educativo que surge de las necesidades de la comunidad, con un estilo de liderazgo que propicia la participación y la construcción colectiva (Riveros, 2010, No. 5).

La gestión participativa requiere de la interacción común para trabajar en equipos que asuman un liderazgo compartido; lo que implica la construcción de nuevas estructuras y la sistematización continua de nuevos conocimientos. Es una gestión que busca la innovación, el trabajo en redes y la comunicación transparente, inclusiva y pertinente.

El liderazgo compartido requiere del compromiso de todos y significa un cambio en la cultura. "De esta forma, el liderazgo distribuido aprovecha las habilidades de los otros en una causa común, de tal forma que el liderazgo se manifiesta a todos los niveles" (Harris y Chapman, 2002). Ernesto Gore, por su parte, invita a modificar los estilos de liderazgo para adaptarlos a las necesidades de aquellos a quienes se les conduce; este estilo de 
liderazgo innovador se encuentra en permanente cambio para lograr un auténtico trabajo en equipo mediante la generación de comunicación, la creación de conocimiento y el crearse a sí mismo, pues "Quien aspire a cambiar una organización debe demostrar que es capaz de cambiarse a sí mismo" (2004, p. 69).

Teniendo en cuenta el escalafón mundial de las 500 mejores universidades a 2011, tan sólo dos instituciones colombianas se insertan en él, la Universidad de los Andes, que se ubicó entre los puestos 401 y 450 (el año pasado estaba en el puesto 513), y la Universidad Nacional, entre las posiciones 450 y 500 (en el 2010 figuró en el puesto 563). Este escalafón tiene en cuenta criterios de producción académica y de investigación, la presencia de docentes y estudiantes extranjeros en las aulas, y el promedio de alumnos por facultad, entre otros. La constatación de esta realidad tiene hondas implicaciones para las instituciones en el ámbito del liderazgo y la gestión.

El Instituto Internacional de Planeamiento de la Educación (IIPE) de la UNESCO (2000), señala que la gestión educativa es un conjunto de procesos teórico-prácticos integrados y relacionados, tanto horizontal como verticalmente, dentro del sistema educativo para atender y cumplir las demandas sociales realizadas a la educación (IIPE UNESCO, 2000).

La gestión educativa se entiende como las acciones desplegadas por los gestores que dirigen amplios espacios organizacionales de un todo que integra conocimiento y acción, ética y eficacia, política y administración de procesos que tienden al mejoramiento continuo de las prácticas educativas, a la exploración y explotación de todas las posibilidades, y a la innovación permanente como proceso sistemático.

Gracias al proceso de innovación de la gestión se han generado conceptos que denotan una actuación distinta de los sujetos a partir del conocimiento producido por la investigación. La gestión educativa con enfoque estratégico es una nueva forma de comprender, organizar y conducir tanto al sistema educativo como a la organización institucional.

Dentro de la Gestión educativa estratégica se hace referencia a estos múltiples aspectos que la integran, a cada uno de los cuales subyace una serie de factores y competencias fundamentales. Este concepto de gestión tiene al menos tres grandes campos de significado y aplicación: 
El primero se relaciona con la acción, es una forma de proceder para conseguir un objetivo o fin determinado por personas. El segundo es el campo de la investigación, donde la gestión trata del proceso formal y sistemático para producir conocimiento sobre los fenómenos observables en el campo de la acción, sea para describir, comprender o explicar tales fenómenos. El tercer campo es el de la innovación y el desarrollo; en éste se crean nuevas pautas de gestión para la acción de los sujetos, con la intención de transformarla o mejorarla, es decir, para enriquecer la acción y hacerla eficiente, porque utiliza mejor los recursos disponibles; eficaz, porque logra los propósitos y fines perseguidos; y pertinente, porque es adecuada al contexto y a las personas que la realizan (Secretaría de Educación Básica de México, 2009, p. 35).

La gestión educativa estratégica articula todos los elementos que componen un proceso de mejora de la calidad; la manera en la que los docentes realizan los procesos pedagógicos, como asumen el currículo y lo traducen en una planeación didáctica, y cómo lo evalúan. Sin dejar de lado la importancia del currículo, entendiendo este como:

Un texto que representa y presenta aspiraciones, intereses, ideales y formas de entender su misión en un contexto histórico muy concreto, desde donde se toman decisiones y se eligen caminos que están afectados por las opciones políticas generales, las económicas, la pertenencia a diferentes medios culturales, etc. [...] La verdad es que su esencia y su sustancia es el resultado de las transformaciones que sobre él provocan prácticas y decisiones políticas, organizativas, pedagógicas, de control [...] (Gimeno, 2010, p. 12).

Según la Secretaría de Educación Básica de México (2009), las Instituciones de Educación Superior deben orientar en forma exigente su currículo y la gestión de este por criterios que orienten a la excelencia.

a. Centralidad en lo pedagógico. Consiste en la generación de aprendizajes para todos los estudiantes desde la organización de los sistemas educativos

b. Reconfiguración, nuevas competencias y profesionalización. Supone la necesidad de que los diversos actores educativos posean los elementos indispensables para la comprensión de los nuevos procesos, oportunidades y soluciones a la diversidad de situaciones. 
c. Trabajo en equipo, que proporcione a la institución una visión compartida acerca de hacia dónde se quiere ir y de cuáles son las concepciones y los principios educativos que se quieren promover.

d. Apertura al aprendizaje y a la innovación. Ésta se basa en la capacidad de los actores de encontrar e implementar nuevas ideas para el logro de sus objetivos educacionales; así como para romper inercias y barreras, favoreciendo la definición de metas y priorizando la transformación integral.

e. Asesoramiento y orientación para la profesionalización. Consiste en que existan espacios de reflexión para la formación permanente, para "pensar el pensamiento", repensar la acción, ampliar el poder epistémico y la voz de los docentes; se trata de habilitar circuitos para identificar áreas de oportunidad y generar redes de intercambio de experiencias en un plan de desarrollo profesional.

f. Culturas organizacionales cohesionadas por una visión de futuro, que se planteen escenarios múltiples ante situaciones diversas, a partir de objetivos claros y consensos de altura para arribar a estadios superiores como institución; donde los actores promuevan una organización inteligente, rica en propuestas y creatividad, que estimulen la participación, la responsabilidad y el compromiso compartido.

g. Intervención sistémica y estratégica. Supone visualizar la situación educativa, elaborar la estrategia y articular acciones para lograr los objetivos y metas que se planteen; hacer de la planificación una herramienta de autorregulación y gobierno para potenciar las capacidades de todos para una intervención con sentido.

El Modelo de Gestión Educativa Estratégica de la Subsecretaría de Educación de México plantea la necesidad de vincular resultados educativos y formas de gestión para generar procesos de transformación que promuevan la mejora en la calidad de las instituciones de educación (2009, p. 35).

En los programas gubernamentales, la calidad en la educación superior constituye una constante preocupación y es motivo de reflexión de los estudiosos del tema. Almaguer, en su artículo "La calidad en la educación pública en México", enfatiza que mientras esta 
preocupación no se inserte en una cultura nacional por la calidad, los resultados seguirán siendo deficientes (Almaguer, 2000).

De acuerdo con el Consejo Nacional de Acreditación, CNA, "El concepto de calidad aplicado a las instituciones de educación superior hace referencia un atributo del servicio público de la educación en general, y en particular, al modo como ese servicio se presta según el tipo de institución de que se trate. Un programa tiene calidad en la medida que haga efectivo su concepto, tanto en relación con sus características universales, como en relación con las características que surgen de su propio proyecto educativo, del campo en que operan y del tipo de institución al que pertenecen" (2009, p. 12).

El CNA estableció, en el documento Lineamientos para la Acreditación del Alta Calidad de Maestrías y Doctorados, el modelo para la evaluación de Alta calidad de programas posgraduales en las IES, comprendido a partir de la estructuración de tres componentes (Factores, características e indicadores), de acuerdo a la siguiente estructuración: 10 factores, 29 características y 95 indicadores. Entre los factores se encuentran:

1. Cumplimiento de los objetivos del programa.

2. Estudiantes

3. Profesores.

4. Procesos académicos y lineamientos curriculares.

5. Investigación: Calidad, pertinencias y producción científica.

6. Articulación con el entorno y capacidad para generar procesos de innovación.

7. Internacionalización, alianzas estratégicas e inserción en redes científicas globales.

8. Bienestar y ambiente institucional.

9. Graduados y análisis de impacto del programa.

10. Recursos físicos y gestión administrativa y financiera (CNA, 2009, p. 19). 


\section{JUSTIFICACIÓN}

La calidad educativa enfrenta un gran desafío: mejorar a partir de lo existente, fortaleciendo una cultura de excelencia y rigurosidad vinculada a procesos y resultados transversales, a la evolución de un sistema educativo innovador y de calidad en el que se involucren todos sus componentes: directivos, estudiantes, docentes; administrativos, institución, contexto socio-cultural y económico, las metas nacionales en tanto políticas de conocimiento ciencia y tecnología, las discusiones del sistema-mundo, las necesidades de internacionalización, entre otros.

Lo interesante del concepto de "mejora" es que "denota un hacer a partir de lo que existe y en este sentido no opera por demolición sino mediante procesos de diálogo y reconstrucción de lo existente" (Romero, 2004, p. 12). En el trabajo conjunto es indispensable tener claros los procesos de planificación, innovación y evaluación, que hacen parte de la gestión educativa y que son necesarios para promover cambios en la realidad universitaria y por ende en la realidad social. De los equipos directivos depende la creación de las condiciones necesarias para que sea posible lograr Instituciones y Programas de Calidad.

El presente artículo enfoca su discusión teórica en la gestión como un eje integrador de las dimensiones y procesos que permiten comprender cómo se ha venido desarrollando el Programa de Doctorado en Educación ofrecido por la Universidad Pedagógica Nacional, para visibilizar aspectos relevantes de su contexto como punto de partida para estudios posteriores y para que la Institución misma pueda diseñar líneas de acción desde problemáticas definidas y construir planes de mejora dirigidos a elevar la calidad de la educación. En la dinámica internacional, los cambios en el ámbito educativo se dirigen a conocer qué aspectos deben cambiarse y cómo efectuar estos cambios, por lo tanto hacer un estudio de estas características es el punto de partida para la implementación de reformas educativas de largo alcance.

Son muchos los elementos que componen la gestión de calidad y muchas las preguntas que surgen al analizar el contexto del doctorado en educación de la UPN. ¿Cuál es la percepción de calidad de directivos, docentes, estudiantes, y egresados a partir de los criterios de los procesos de formación doctoral? ¿Puede el Programa de Doctorado en educación responder a los estándares de calidad nacional e internacional con su actual 
estructura organizacional y de gestión? ¿Cuál es el concepto de calidad de directivos, docentes, estudiantes y egresados a partir de los criterios de los procesos de formación doctoral? ¿Son pertinentes las acciones impulsadas por el currículo para responder a los objetivos misionales del Programa? ¿Qué es necesario cambiar? ¿Qué hace falta para que el nivel y el número de doctorados en educación aumenten en Colombia?

Las preguntas planteadas son el preámbulo para la indagación de los aspectos que orientan la medición de los procesos de gestión para la calidad y van a analizarse de manera crítica para identificar oportunidades de cambio que contribuyan al fortalecimiento de políticas institucionales y, por qué no, nacionales.

De acuerdo con el Documento Técnico No. 5 de la UNESCO (2010) Medición de la Investigación y el Desarrollo $(I+D)$ : Desafíos enfrentados por los países en desarrollo, "en la actualidad, la investigación y la innovación se reconocen a nivel mundial como unos de los principales motores del desarrollo económico tanto de países en desarrollo como desarrollados, convirtiéndose, por consiguiente, en una importante fuerza promotora de la mitigación de la pobreza. En Colombia, la formación y producción de investigación se centra principalmente en las Instituciones de Educación Superior, universidades, centros de alta tecnología y, con gran impacto pero en menor medida, en algunas empresas que buscan innovar y optimizar procesos productivos, atendiendo específicamente al contexto del mercado laboral y a necesidades de competitividad.

El Departamento Administrativo de Ciencia y Tecnología de Colombia, COLCIENCIAS, dentro de su Plan Estratégico Nacional de Ciencia Tecnología e Innovación 2011, plantea como visión para el año 2014 que "Colombia habrá consolidado una Política de Estado en ciencia, tecnología e innovación mediante el incremento en la producción, uso, integración y apropiación del conocimiento en el aparato productivo y en la sociedad en general, que contribuya al progreso social, al dinamismo económico, al crecimiento sostenido y sostenible y a una mayor prosperidad para toda la población". Para el año 2019 se plantea como visión, en este mismo documento, que "Colombia tendrá un desarrollo humano, social y económico cimentado en la Producción, difusión y uso del conocimiento que será un elemento fundamental para la productividad y la competitividad internacional y la prevención y solución de problemas nacionales y regionales”. 
Estos horizontes permiten cuestionarse sobre la Calidad de los procesos de formación y producción de investigación en el país; teniendo en cuenta que para el alcance de las metas mencionadas se requiere que "la comunidad científica y tecnológica nacional tenga herramientas necesarias para producir y aplicar conocimiento de excelencia que contribuya a la solución de los problemas del país", lo cual no puede darse sin un capital humano con las habilidades y competencias idóneas para la producción de investigación e innovación, que tenga las habilidades y competencias para la ciencia, para lo que se destaca la formación de doctores.

Las preocupaciones por la calidad se amplían al tener en cuenta el creciente número de nuevas instituciones educativas y el aumento de la oferta de gran variedad de programas académicos en el nivel de posgrado que atienden a las diversas dinámicas de los contextos laborales, así como las escasas estrategias e instrumentos que den cuenta de un aumento proporcional de la producción en investigación, coherente con el aumento de Programas.

En la actualidad, se identifican tres niveles académicos más o menos estándar dentro de la categoría de posgrado: Especialización, Maestría y Doctorado. En Colombia y Ecuador, se utiliza además la figura de Diplomado como un nivel de formación de menor complejidad y duración. Para Cruz Cardona (2005), al posgrado se lo concibe como la formación de nivel avanzado cuyo propósito central es la preparación para la docencia, la investigación, la aplicación tecnológica o el ejercicio especializado de una profesión.

Los Programas Académicos de posgrado han tenido un acelerado y espontáneo crecimiento en las últimas décadas, respondiendo a potencialidades y esfuerzos de diferentes estamentos. No obstante, este crecimiento acelerado de ofertas de posgrado se dan en un contexto caracterizado, entre otros aspectos, por: "Escasas estructuras estatales para promover, financiar y coordinarlos; falta de pertinencia científica y social a los programas; escasa producción científica; ausencia comunicacional y de convalidación de estudios y títulos; alta concentración en disciplinas tradicionales en principales universidades y capitales de países; dificultad de las Universidades para articular programas de pregrado y posgrado" (Videla, 2008).

El aumento reciente en la oferta de posgrados en Colombia puede ser explicado por diversos factores: "mayores exigencias en el mercado laboral, la depreciación de los 
títulos de grado y las orientaciones de las leyes de Educación Superior en relación con la formación de docentes, incrementan la demanda por este tipo de estudios". Por otra parte, los posgrados se han convertido en una fuente de ingresos importante para las instituciones de Educación, ya que este nivel de estudios tiene un costo mayor en comparación con los pregrados por los niveles de especialización.

De acuerdo con el Informe Indicadores de ciencia y Tecnología: Colombia 2010, del Observatorio Colombiano de Ciencia y Tecnología, OCyT, en el año 2000, en el área de la OCDE Ciencias sociales y Humanidades, había un total de 13 programas de doctorado, en tanto que para el 2009 el número aumentó a 65. En el campo específico de los doctorados en Educción, para el año 2000 se contaba con 03 doctorados y para el 2009 la cifra aumentó a 13 programas (OCyT, 2010, p. 45).

Gráfico 1. Doctorados en Colombia: Por área de conocimiento (2001-2009)

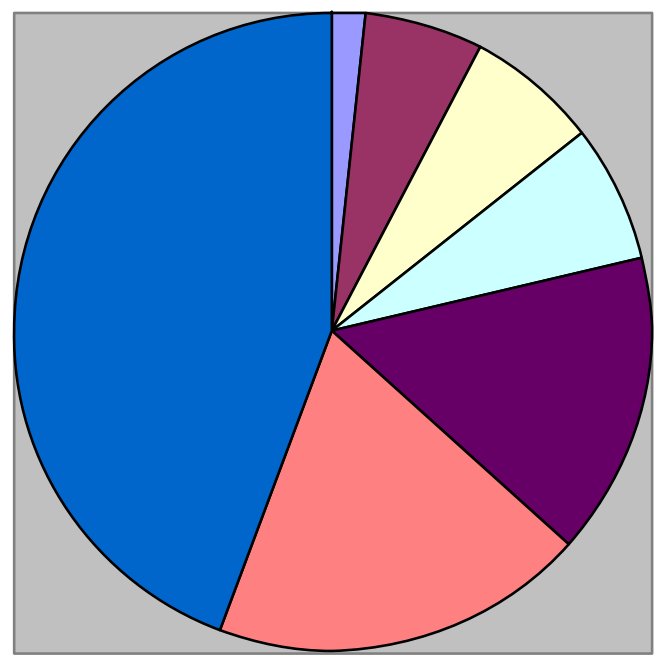

口ECON., ADMIN., CONT. $\square$ C. DE LA EDUCACIÓN $\square$ AGRONOMÍA Y VETERINARIA. $\square$ C. DE LA SALUD

- C. SOCIALES Y HUMNAS $\square$ ING.,ARQ. Y URBANISMO $\square$ CIENCIAS BÁSICAS

Fuente: Revista Posgrados 2010 - 2011. Edit. Legis. (p.18)

Tabla 1. Doctorados en Colombia: por área de conocimiento (2001-2009)

\begin{tabular}{|c|l|l|}
\hline PUESTO & $\begin{array}{c}\text { NÚMERO DE } \\
\text { DOCTORES }\end{array}$ & \multicolumn{1}{|c|}{ ÁREA DE CONOCIMIENTO } \\
\hline 1 & 297 & Ciencias básicas \\
\hline 2 & 126 & Ingeniería, arquitectura y urbanismo \\
\hline
\end{tabular}




\begin{tabular}{|l|l|l|}
\hline 3 & 103 & Ciencias sociales y humanas \\
\hline 4 & 46 & Ciencias de la salud \\
\hline 5 & 45 & Agronomía y veterinaria \\
\hline 6 & 40 & Ciencias de la educación \\
\hline 7 & 12 & Economía, administración y contaduría \\
\hline \multicolumn{3}{|c|}{669 DOCTORES GRADUADOS EN 2001-2009 } \\
\hline
\end{tabular}

Fuente: Elaboración propia.

Surgen muchas inquietudes con respecto al incremento de doctorados en el año 2006 y 2007, al saltarse a un nivel de más de 100 doctores por año. Esto se debe al esfuerzo que comenzaron a realizar varias universidades orientadas a fomentar e incentivar la graduación de doctores, con el fin de contrarrestar la tendencia a alargar los estudios de doctorado debido al tiempo que está tomando la preparación de la tesis. Los años que se requieren para graduarse están excediendo los 5 y 7 años, como se evidencia en el documento del CNA "Situación actual de los doctorados en Colombia: análisis de indicadores que tipifican características importantes" (2008).

Entre el 2001 y el 2004 se establecen nuevos doctorados en áreas del conocimiento en las que no había doctorados anteriormente, como es el caso de Ciencias de la Educación, Ciencias Agropecuarias, Ciencias Sociales y Humanas, y Economía. De estos cuatro campos, los dos que más rápido crecieron son Ciencias de la Educación, y Ciencias Sociales y Humanas; en el último año se graduaron entre 11 y 14 doctores.

Tabla 2. Distribución de los principales indicadores por año de creación

\begin{tabular}{|c|c|c|c|c|c|c|c|c|c|c|}
\hline \multirow{2}{*}{$\begin{array}{c}\text { Área del } \\
\text { Conocimiento }\end{array}$} & \multirow{2}{*}{ Doctorados } & \multirow{2}{*}{$\begin{array}{l}\text { Estud. } \\
2007\end{array}$} & \multicolumn{2}{|c|}{$\begin{array}{c}\text { Profesores } \\
2007\end{array}$} & \multirow{2}{*}{$\begin{array}{l}\text { Doctores } \\
\text { graduados }\end{array}$} & \multicolumn{2}{|c|}{$\begin{array}{l}\text { Grs. De } \\
\text { Investig }\end{array}$} & \multicolumn{3}{|c|}{$\begin{array}{c}\text { Publicaciones } \\
\text { Indexadas }\end{array}$} \\
\hline & & & Planta & Doct. & & A & B & ISI & $\begin{array}{c}\text { Otras } \\
\text { BD }\end{array}$ & Total \\
\hline $\begin{array}{l}\text { Ciencias Naturales y } \\
\text { Matemáticas }\end{array}$ & 23 & 492 & 488 & 460 & 276 & 139 & 47 & 2.415 & 703 & 3.118 \\
\hline $\begin{array}{l}\text { Ingeniería, } \\
\text { Arquitectura y Afines }\end{array}$ & 18 & 419 & 371 & 348 & 73 & 94 & 34 & 1.272 & 732 & 2.004 \\
\hline
\end{tabular}




\begin{tabular}{|l|c|c|c|c|c|c|c|c|c|c|}
\hline Filosofía y Teología & 6 & 118 & 102 & 87 & 61 & 14 & 9 & 51 & 51 & 102 \\
\hline $\begin{array}{l}\text { Ciencias de la } \\
\text { Educación }\end{array}$ & 9 & 307 & 137 & 128 & 54 & 44 & 22 & 37 & 241 & 278 \\
\hline $\begin{array}{l}\text { Agronomía, } \\
\text { Veterinaria y Afines }\end{array}$ & 6 & 98 & 178 & 114 & 43 & 20 & 7 & 396 & 282 & 678 \\
\hline $\begin{array}{l}\text { Ciencias Sociales y } \\
\text { Humanas }\end{array}$ & 14 & 309 & 178 & 173 & 35 & 42 & 25 & 75 & 434 & 509 \\
\hline $\begin{array}{l}\text { Ciencias de la Salud } \\
\text { Derecho }\end{array}$ & 3 & 124 & 162 & 126 & 29 & 57 & 10 & 560 & 129 & 689 \\
\hline $\begin{array}{l}\text { Economía, } \\
\text { Administración y } \\
\text { Afines }\end{array}$ & 5 & 53 & 75 & 73 & 6 & 13 & 3 & 124 & 151 & 275 \\
\hline Total & 92 & 1.946 & $\mathbf{1 . 7 4 8}$ & $\mathbf{1 . 5 6 4}$ & $\mathbf{5 8 4}$ & $\mathbf{4 3 0}$ & $\mathbf{1 6 0}$ & $\mathbf{4 . 9 3 0}$ & $\mathbf{2 . 7 9 7}$ & $\mathbf{7 . 7 2 7}$ \\
\hline
\end{tabular}

Fuente: Documento Situación actual de los doctorados en Colombia (CNA, 2008).

En la tabla anterior se observa que casi la mitad de los doctorados que existen en Colombia (42 de 92) han sido creados en los últimos cinco años (2003-2007). El desarrollo de los doctorados en Colombia en los últimos 20 años se resume muy bien en la Tabla 2, al analizar el número de doctorados creados durante los últimos cinco cuatrenios (p. 7). La evolución es contundente, al pasar de 9 (1986-1990), a 8 (19911994), a 19 (1995-1998), a 14 (1999-2002) y a 42 en el último período (2003-2007).

El número de doctores que saldrán de las universidades colombianas se incrementará significativamente en los próximos años simplemente como consecuencia de la entrada en funcionamiento pleno de los 42 doctorados establecidos en los últimos cuatro años. Debido a su muy reciente creación (algunos apenas fueron aprobados por el CONACES en el 2006 y el 2007). Estos doctorados todavía no han comenzado a graduar doctores, sin embargo estos niveles de formación doctoral no corresponden a la demanda; nuestro país sigue estando proporcionalmente muy por debajo de los estándares internacionales. A pesar del notorio incremento en el número de doctores que se gradúan por año, el total de doctores sigue siendo muy bajo en comparación con los niveles de formación doctoral que se puede observar en otros países Iberoamericanos con un nivel de desarrollo socioeconómico comparable o con otros países del mundo que buscan insertarse en la economía global del conocimiento. 
En la tabla de becas, créditos y becas-crédito para doctorado se encontró que mientras que en el 2000 las becas para los programas de doctorado en el área de ciencias sociales y humanas fueron tan sólo 19; en el 2009 aumentó significativamente a un total de 153. (OCyT, 2010, p. 49). Sin embargo, aunque el número de programas de doctorado en educación aumentó en el país al igual que el número de becas o créditos entregados a doctorandos, la proporción continúa siendo muy baja en comparación con las demás áreas del conocimiento.

De acuerdo con el mismo informe de la OCyT, el Programa Nacional de Ciencia y Tecnología: Estudios Científicos de la Educación aparece en el listado con los más bajos indicadores en la Tabla Proyectos Financiados por COLCIENCIAS; para el año 2000 aparece con un total de 31 , correspondiente a un total de $13.66 \%$ del total de proyectos financiados, mientras que para el 2009 pasó a 9, bajando así a un 3.15\% del total de la financiación nacional de proyectos en diferentes áreas de conocimiento. En comparación, se pueden analizar las mismas cifras pero para el caso del Programa Nacional de Ciencia y Tecnología de la Salud, que para el 2000 contó con 43 proyectos financiados correspondientes al $18.94 \%$ del total de proyectos-, y para el 2009 aumentó significativamente a 83 proyectos -para un total del $29.02 \%$-. La financiación de proyectos relacionados con los programas doctorales en educación es insignificante si se compara con otras aéreas de conocimiento. La Dra. Rosalba Pulido, Directora del Doctorado Interinstitucional de Educación, Sede Bogotá, afirma: "En Colombia los estudios en educación reciben menos presupuestos que las ingenierías”.

Estos indicadores negativos sobre la financiación de proyectos en programas de educación se deben a varias razones, entre otras: pocas propuestas estructuradas de investigación generadas en el escenario de los programas doctorales, políticas nacionales de ciencia y tecnología que dan baja prioridad a los proyectos de investigación del área de educación en lo relacionado con las metas nacionales de conocimiento en pro del desarrollo productivo del país, propuestas con un impacto limitado, desconocimiento de las convocatorias de financiación por problemas de gestión y comunicación al interior de los programas doctorales.

A través del aplicativo DocLAC, el Departamento Administrativo de Ciencia y Tecnología COLCIENCIAS hace un seguimiento a los procesos académicos y organizacionales de los 
Programas Doctorales en Colombia. Utilizando esta herramienta se hizo una búsqueda de los programas doctorales en Educación del país, indagando por los criterios de calidad de los mismos, a saber: Investigadores invitados al doctorado, coordinadores de tesis externos a la institución, egresados, estudiantes inscritos, estudiantes activos y número de docentes (ver Gráfico 2).

Los indicadores más destacados de los doctorados en educación en el país se concentran en tres instituciones principalmente: la Universidad Pedagógica Nacional, la Universidad Distrital Francisco José de Caldas y la Universidad del Valle, quienes han unido esfuerzos e instituido el Doctorado Interinstitucional en Educación, en el cual, aunque fue aprobado gracias a la alianza estratégica entre las tres instituciones, cada sede del mismo maneja su propio registro de DocLAC; permitiendo tener información del funcionamiento del doctorado discriminado por cada región donde se desarrolla.

\section{Gráfico 2.}




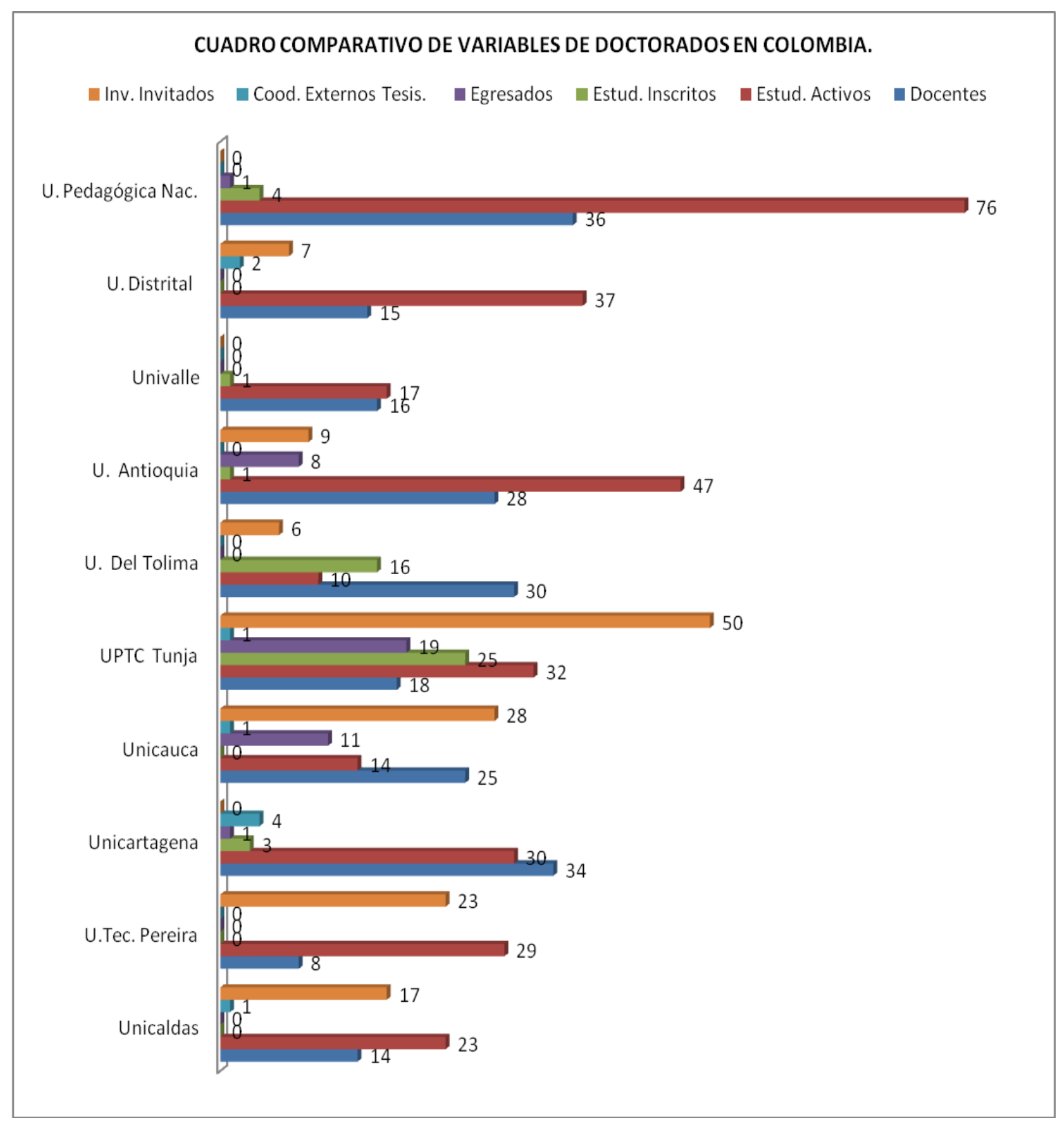

Fuente: Elaboración propia

De acuerdo con el documento marco mediante el cual se ratifica el Programa Doctoral Interinstitucional, este proyecto:

Busca responder al esfuerzo en que está empeñado el país por fortalecer y consolidar su capacidad científica y tecnológica y por cambiar la relación de los colombianos con el conocimiento, promoviendo y facilitando nuevas oportunidades de información, apropiación y producción de conocimiento, a través del fomento y la consolidación de una cultura de la investigación. De 
igual manera, este proyecto se relaciona con el Programa Nacional de Ciencia y Tecnología, que de acuerdo con el Decreto 585 del 26 de febrero de 1991, establece, entre otros, el Programa de Estudios Científicos en Educación (Decreto 585/91 Art. 5ํ).

La Universidad ha tenido una notable evolución según las exigencias de las sociedades de conocimiento, pues se aleja de la función específicamente profesionalizante y se fortalece orientándose hacia la economía de uso y generación del conocimiento a partir de la cualificación de su capital humano. De acuerdo con la Doctora Rosalba Pulido, Directora del Doctorado Interinstitucional de Educación, Sede Bogotá-Universidad Pedagógica Nacional:

En los años 90, se realizó una primera propuesta de formación doctoral organizada interinstitucionalmente. La idea de lo interinstitucional deviene de la necesidad de fortalecer capacidades, aprovechar las ventajas comparativas de las instituciones y generar procesos que posibiliten el desarrollo de todas las Instituciones. En el primer doctorado participaron 5 universidades; algunas como gerentes, Universidad Pedagógica, Universidad de Antioquia y Universidad del Valle, en tanto que había otras instituciones bajo la figura de participantes, Universidad Nacional de Colombia, sede Bogotá, Universidad Industrial de Santander, UIS. Esa propuesta con el proceso de renovación de registro calificado y demás, fue presentada en su momento por la Universidad de Antioquia; sin embargo, se presentaron algunos problemas y fue necesario retirar los documentos. Así, se elaboró otra propuesta y en este momento el Doctorado está conformado por tres universidades: Una Nacional, una Departamental y una Distrital.

El doctorado busca: Aunar esfuerzos, contribuir al desarrollo del campo educativo. En este se asume que la educación, la pedagogía y la didáctica, constituyen campos de saber que pueden generar alternativas para formación de doctores, logrando que el trabajo de éstos contribuya en el país a cualificar la educación en todos los niveles y desarrollar más conocimiento, al tiempo de tener procesos pertinentes desde la idea de un desarrollo nacional sobre la base del desarrollo de las personas (Fragmento Entrevista realizada).

Teniendo en cuenta que los resultados más significativos en cuanto a indicadores de producción de investigación los ofrecen las Instituciones participantes del Doctorado Interinstitucional de Educación mencionadas anteriormente, se decidió tomarlos como 
referente para centrar el estudio que interesa a los objetivos planteados. Sin embargo, se obliga para los intereses de la investigación a delimitar aún más el campo de estudio. Por tanto, teniendo en cuenta la información dada por el DocLAC, se indagó por los indicadores de calidad más destacados entre las tres instituciones, centrándose en la que mejores indicadores presentan para aplicar en ésta el instrumento de percepción que permita profundizar en la indagación acerca de la calidad de los procesos de formación doctoral en el campo de la educación.

Los indicadores interesantes del Doctorado Interdisciplinar se fundamentan principalmente en que en las tres instituciones el programa es sustentado en la trayectoria de los grupos de investigación; los cuales tienen varios años de trabajo previo y producción de investigación. De acuerdo con el documento marco que institucionaliza la alianza de las tres universidades, "el desarrollo investigativo de los grupos [...] está respaldado por profesores con título de doctor y por la infraestructura con la que cuenta cada Universidad participante del convenio. Además, contará con el apoyo de instituciones internacionales a través de convenios".

\section{Gráfico 3.}

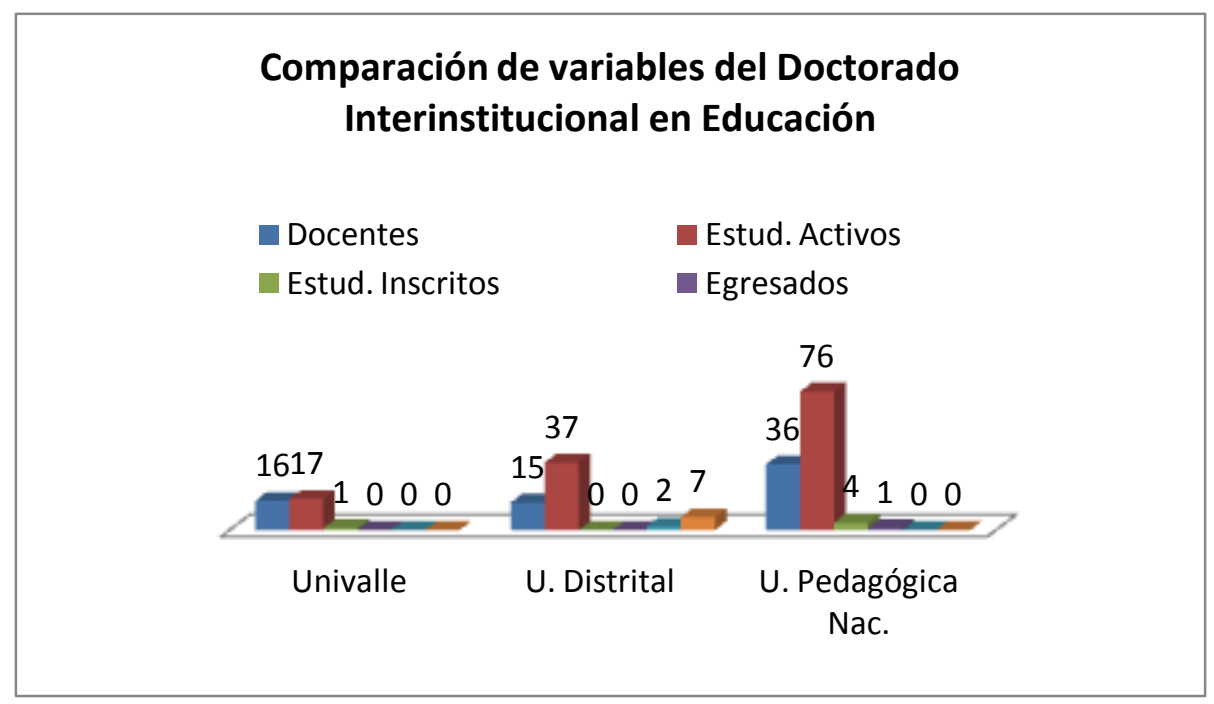

Fuente: Elaboración propia

\section{Gráfico 4}




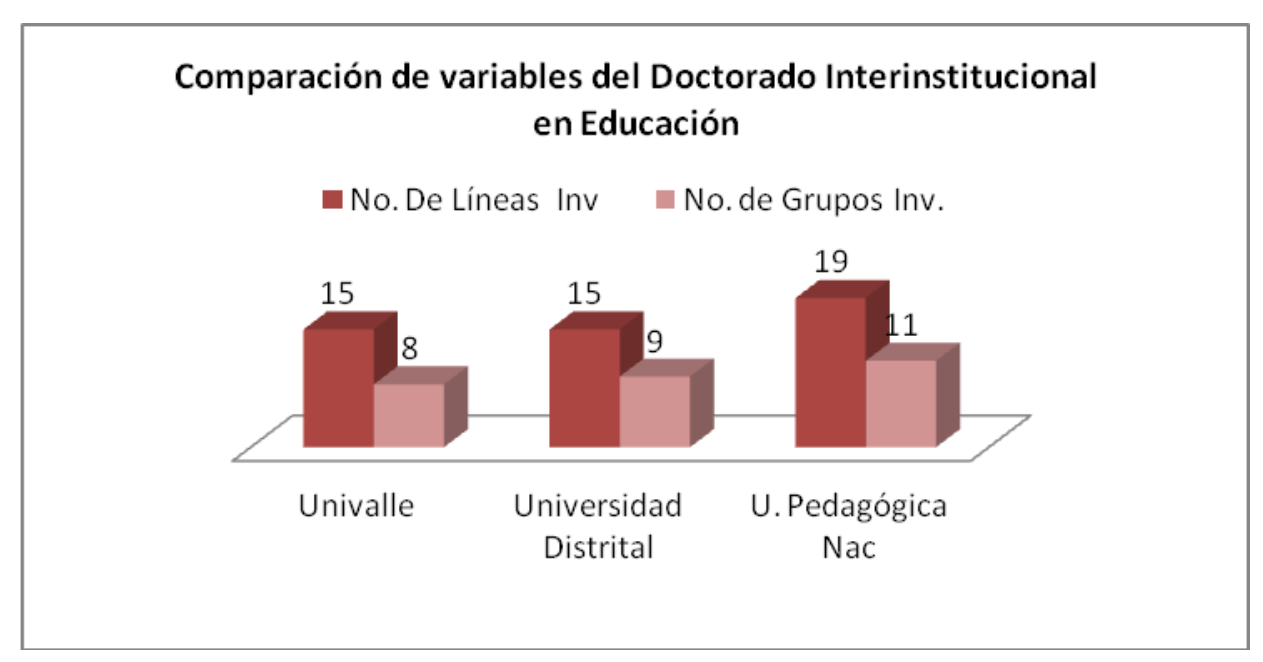

Fuente: Elaboración propia

\section{Gráfico 5}

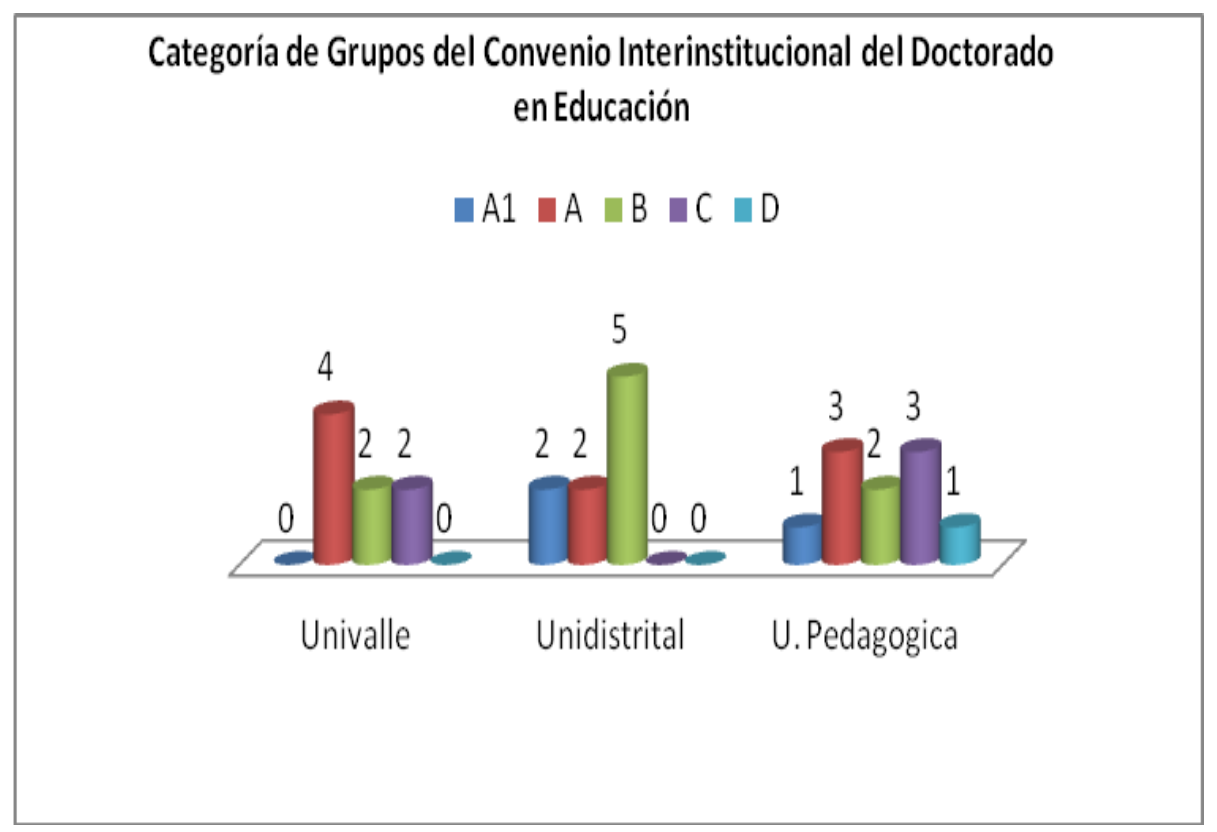

Fuente: Elaboración propia

La información de los DocLAc de las tres instituciones presenta a la Universidad Pedagógica Nacional de la ciudad Bogotá como la institución con los porcentajes más elevados en relación con los indicadores tenidos en cuenta, como: No. de docentes Vs No. de estudiantes, No. de egresados, No. de estudiantes activos e inscritos, investigadores invitados y coordinadores externos de tesis (Gráfico 3); al igual que el 
número de líneas y de grupos de investigación (Gráfico 4) con su respectiva clasificación otorgada por COLCIENCIAS (Gráfico 5).

Este tipo de información, permite inferir que la Universidad Pedagógica Nacional tiene un desarrollo más integral en lo relacionado a la producción de investigación, pues cuenta con grupos en todas las categorías que otorga COLCIENCIAS en sus convocatorias de medición de grupos, sobresaliendo por sobre las demás tanto por su número de grupos de investigación como por el número de docentes, estudiantes activos e investigadores invitados vinculados a este Programa Académico.

Gráfico 6. Producción de los grupos de investigación que soportan el programa

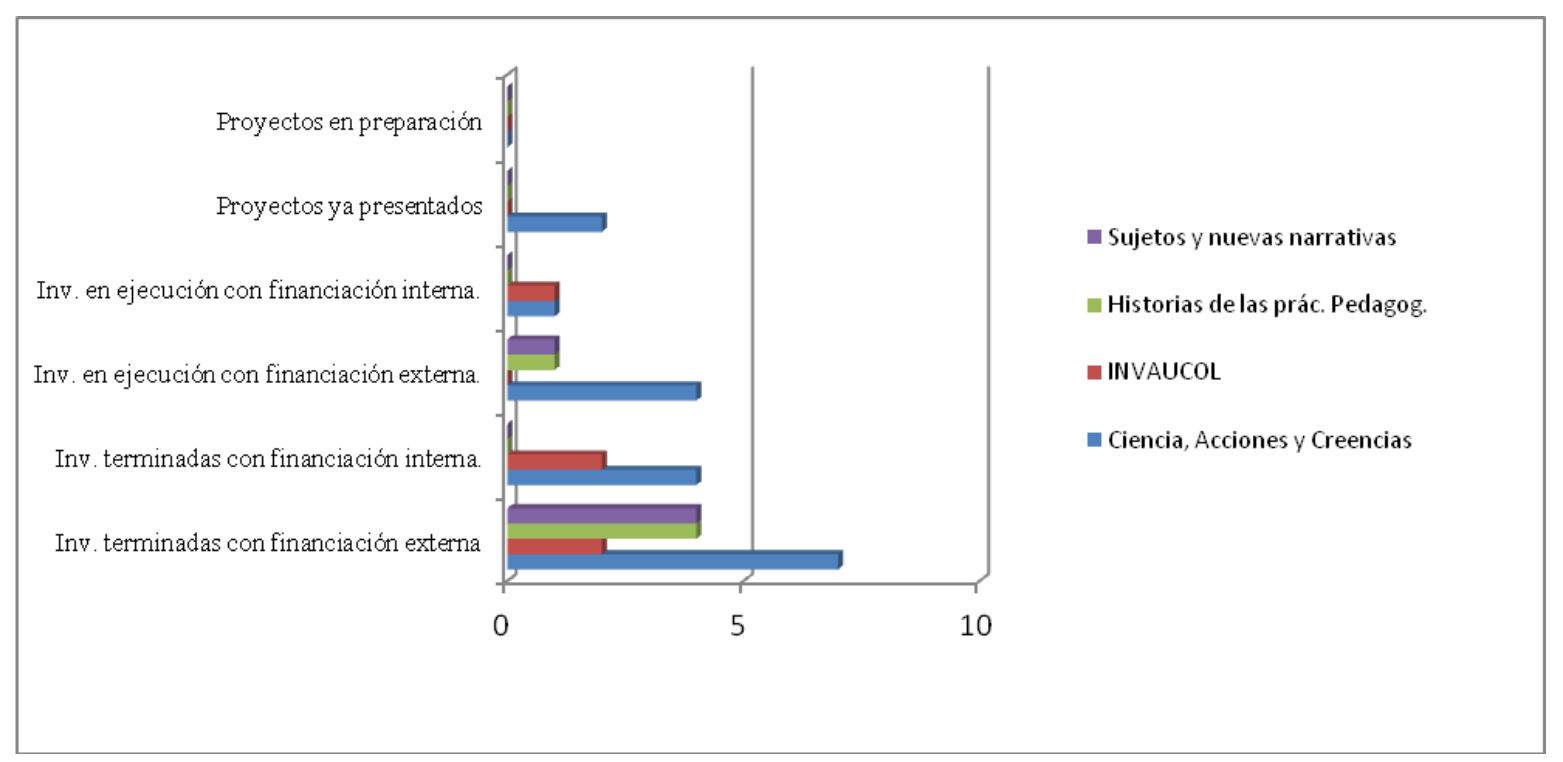

Fuente: Doctorado Interinstitucional en Educación. Documento Marco. Universidad Pedagógica Nacional.

Sin embargo, es importante analizar que la realización de proyectos de investigación no es muy alentadora, pues tan sólo un (01) grupo de investigación, Ciencia, acciones y creencias, tiene una producción significativa. Alerta también la baja planeación y reserva de proyectos en preparación que garanticen el trabajo a futuro del grupo, lo cual hace pensar en una falta de misión y visión a largo plazo, tanto del equipo humano que hace parte del grupo, como del Centro de Investigaciones de la Universidad.

\section{Gráfico 7.}




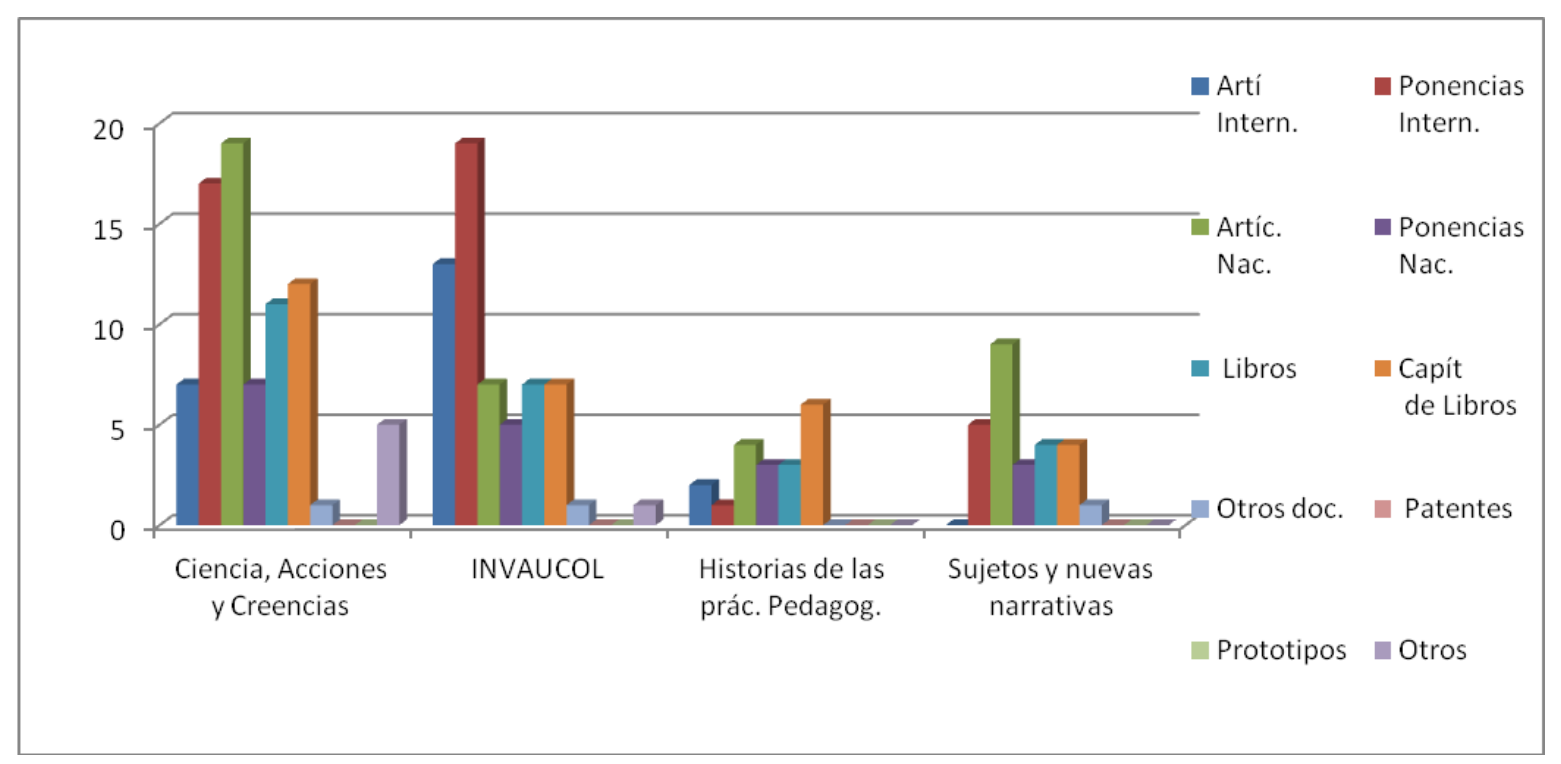

Fuente: Doctorado Interinstitucional en Educación. Documento Marco. Universidad Pedagógica Nacional.

De igual manera, vale profundizar en la cantidad y el tipo de producción académica y de investigación de los Grupos de Investigación de la Universidad Pedagógica Nacional. Teniendo en cuenta el Documento Marco del Doctorado Interinstitucional en Educación, se retomaron los grupos de investigación más antiguos de la Universidad y se midió la producción según los criterios indicados en el Gráfico 6, en el que sorprenden los bajos resultados de los grupos de investigación en producción relacionada con: Patentes o registros, otros documentos, prototipos y otros. Al igual que el poco número de artículos de investigación publicada en revistas internacionales. Resultados que alarman si se tiene en cuenta que en promedio estos son los grupos con mejores indicadores entre las Instituciones Universitarias que ofrecen Programas doctorales en educación.

Este fenómeno, permite la reflexión sobre si deberían o no existir indicadores diferenciales para valorar los productos investigativos de las llamadas Ciencias Duras y las Ciencias Blandas, teniendo en cuenta que las dinámicas, prácticas y formas de producción de conocimiento no se dan de la mima manera para ambos casos. Lo anterior, pues no resulta del todo comprensible que a las áreas de conocimiento mal relacionadas con las Ciencias Blandas se les mida la producción en investigación utilizando la variable de patentes, registros o prototipos comercializables cuando no se encuentra de manera normalizada el trabajo en este tipo de productos entre los científicos de estas disciplinas. Se esperaría que en los estándares de medición de producción científica se diera un peso 
igual o, por qué no, superior a los productos de investigación innovadores y creativos que se relacionen más con el objeto de conocimiento que se aborda en la investigación de las ciencias de la educación; los cuales encuentran más congruencias con estos procesos que los prototipos o las patentes.

\section{La presentación audiovisual como producto del proceso de investigativo en el área de Educación}

El siglo XXI se ha caracterizado por una sociedad que goza de sobreoferta informativa de saberes descentralizados donde la formación integral debe apuntar a la lectura crítica y producción de medios audiovisuales que cuestionen y generen investigación, problematicen y aporten a la búsqueda de soluciones o a mejorar las condiciones a partir de la lectura permanente del texto y el contexto. El producto audiovisual es la maduración y consolidación de una idea a través de un proceso creativo, democrático y lúdico que pone a prueba el uso de las TIC, nuevas tecnologías de la informática y la comunicación en el contexto educativo.

Para llegar a la apreciación cinematográfica y las lecturas semiológicas, el proceso ha involucrado a todo el equipo de trabajo en la consecución de metas a corto, mediano y largo plazo como la frase de presentación, una sinopsis que cautive al público, la división de la historia en escenas por lugar y tiempo, la creación de los diálogos con descripciones detalladas de movimientos y actitudes, la especificidad de los planos requeridos para dar profundidad o la panorámica que contextualiza la situación son aspectos que deben ser discutidos y llevados a acuerdos para lograr una buena composición de imágenes que serán acentuadas por los recursos estilísticos audiovisuales y el sonido audiovisual.

Un producto creativo, fruto de una innovación y consecución colectiva que hace lectura de un contexto, lo critica y le aporta soluciones o alternativas de cambio para mejorar una situación determinada, es un desafío para el docente investigador, innovador y mediador.

Fernando Vásquez Rodríguez, en su obra Educar con Maestría, señala ocho puntos sobre las relaciones entre las nuevas tecnologías, la comunicación y la educación:

1. La distinción de base que hay que hacer entre medios y mediaciones. 
2. La necesidad de superar comprensivamente el deslumbramiento de lo tecnológico.

3. La revisión a esas nuevas y ya antiguas tecnologías que aún hoy no acabamos de aprender.

4. Los nuevos aprendizajes jalonados desde la simulación y no desde estrategias de representación.

5. El papel de la abducción y sus aportes a la teoría de los juegos y del aprendizaje.

6. Crítica a la falsa idea de que acceder o "bajar la información" es tanto como aprenderla.

7. El desplazamiento de formas de enseñanza del único plato o el único camino a las formas articuladas desde el menú o la red.

8. Los medios masivos como construcciones de una visión de la realidad y el maestro como constructor de tomas de distancia frente a los medios (Vásquez, 2007, pp. 39-45).

Dicho en otras palabras:

1. El maestro como mediador utiliza intencionalmente los medios.

2. Las tecnologías deben ser incorporadas a la cotidianidad.

3. Las tecnologías de cada época sirven como mediadores en la transformación del mundo interior y exterior.

4. A través de una pantalla entran a interactuar lo real y lo virtual, privilegiando el sentido de la vista.

5. La praxis brinda elementos de juicio para las normas propias del juego de cada interacción.

6. El conocimiento va más allá de la recopilación de la información, se debe hacer algo con ese puñado de información pertinente para una situación determinada.

7. La funcionalidad y autonomía construyen caminos diversos o redes en la búsqueda del conocimiento.

8. La producción e interpretación de los signos construyen el tejido cultural. 
Visto así la presentación audiovisual como producto del proceso educativo es una oportunidad y una propuesta para la consolidación de un objeto de alta calidad cuyos procesos implican la apropiación crítica de las tecnologías de la informática y la comunicación, donde la autenticidad, credibilidad, representatividad e interpretación del significado son algunos de los indicadores para tener en cuenta en el momento de su valoración (Valles, 2000, pp. 132-137).

La presentación audiovisual entraña una intención, que tomará forma por medio de los recursos audiovisuales, donde se incorporan las tecnologías de la informática en la digitalización y edición de los materiales recolectados y en su comunicación: en la construcción de los respectivos guiones técnicos y literarios originados de las expectativas propias de el autor o grupo de autores y actores que intervienen en el proceso, donde la información debe ser útil y productiva, funcional e interactiva con otros lenguajes, formando vínculo o por lo menos dejando el reto planteado para nuevas redes de conocimiento y representación.

\begin{tabular}{|c|c|c|}
\hline \multicolumn{3}{|c|}{ INDICADORES DE CALIDAD - PRODUCTO AUDIOVISUAL } \\
\hline Pre-producción & Producción & Post-producción \\
\hline $\begin{array}{l}\text { Sinopsis, planteamiento de } \\
\text { escenas con lugar y tiempo o } \\
\text { concepto a trabajar, argumentos, } \\
\text { diálogos y entrevistas de los } \\
\text { diferentes actores previamente } \\
\text { caracterizados y personificados, } \\
\text { implementación de recursos } \\
\text { técnicos propios del lenguaje } \\
\text { audiovisual en tomas y planos }\end{array}$ & $\begin{array}{l}\text { Desarrollar artísticamente el diálogo entre } \\
\text { los guiones técnico y literario } \\
\text { maximizando los elementos de la } \\
\text { producción para dar realce a esos } \\
\text { aspectos sobre los cuales se quiere } \\
\text { llamar la atención recreando escenas } \\
\text { armónicas con las voces lugares y } \\
\text { sonidos que comunican el mensaje que } \\
\text { se quiere llevar a un público determinado. }\end{array}$ & $\begin{array}{l}\text { Proceso de divulgación, } \\
\text { puesta en escena del } \\
\text { producto audiovisual y } \\
\text { retroalimentación que } \\
\text { acredite la autenticidad, } \\
\text { credibilidad, y modelación } \\
\text { de un problema } \\
\text { significativo. }\end{array}$ \\
\hline
\end{tabular}

\section{Productos de Innovación en Educación: Otra opción a considerar}

La palabra innovación es un término polisémico y complejo por su polivalencia y aplicación a diferentes áreas de conocimiento, donde convergen diferentes interpretaciones y perspectivas. También depende del ámbito de acción donde se desarrolle, ya sea político, social, personal o educativo; en este último "la innovación puede ser entendida de diversas maneras, debido a que en el sistema educativo 
intervienen diferentes actores, tales como investigadores, administradores, maestros, padres, estudiantes, entre otros; que de una manera u otra intervienen con su pluralidad u óptica para abordar y entender el tema" (Alfonzo, 2008).

Se tiende a confundir los términos innovación con reforma y cambio. Para aclarar estos conceptos, González (1987, p. 13) cita a Sack (1981), quien considera: que una reforma es un cambio a gran escala, es una forma especial de cambio que implica una estrategia planificada para la modificación de ciertos aspectos del sistema educativo de una país; por otra parte, el término innovación se refiere a cambios de menor escala más concretos: un intento más puntual para mejorar o modificar determinados aspectos del proceso de educación.

Al referirse a los cambios y transformaciones en educación, Aguerrondo (en Gvirtz, S. \& Podestá, 2007), afirma: "lo que se necesita hoy no es un cambio cualquiera, no necesitamos un pequeño cambio, necesitamos lo que se llama un cambio de paradigma. Es importante entender esto porque no es lo mismo cualquier cambio para responder a las necesidades que hoy se postulan para cambiar la educación”.

Existen distintos tipos de cambio, afirma Aguerrondo, "algunos más profundos que otros. Clasificando los cambios según sus profundidades, se puede, o bien mejorar el paradigma actual, que es lo que se ha hecho durante las primeras tres revoluciones (hemos ido agregando cosas a la propuesta clásica para mejorarla), o bien cambiar el paradigma". Explica que si se mejora el paradigma, se está mejorando lo que se ve desde afuera, se mejora lo superficial, pero no en un mal sentido sino en el sentido de lo que se ve en la superficie.

Para cambiar el paradigma, explica (p. 96), hay que ir a lo estructural, a lo más profundo, a lo que está debajo, es decir que el cambio puede ser micro o puede ser macro. En este sentido los cambios estructurales son a nivel micro, y los denomina innovaciones, y a nivel macro se refiere a las transformaciones; y explica estos conceptos por medio del siguiente gráfico: 


\section{Gráfico 8.}

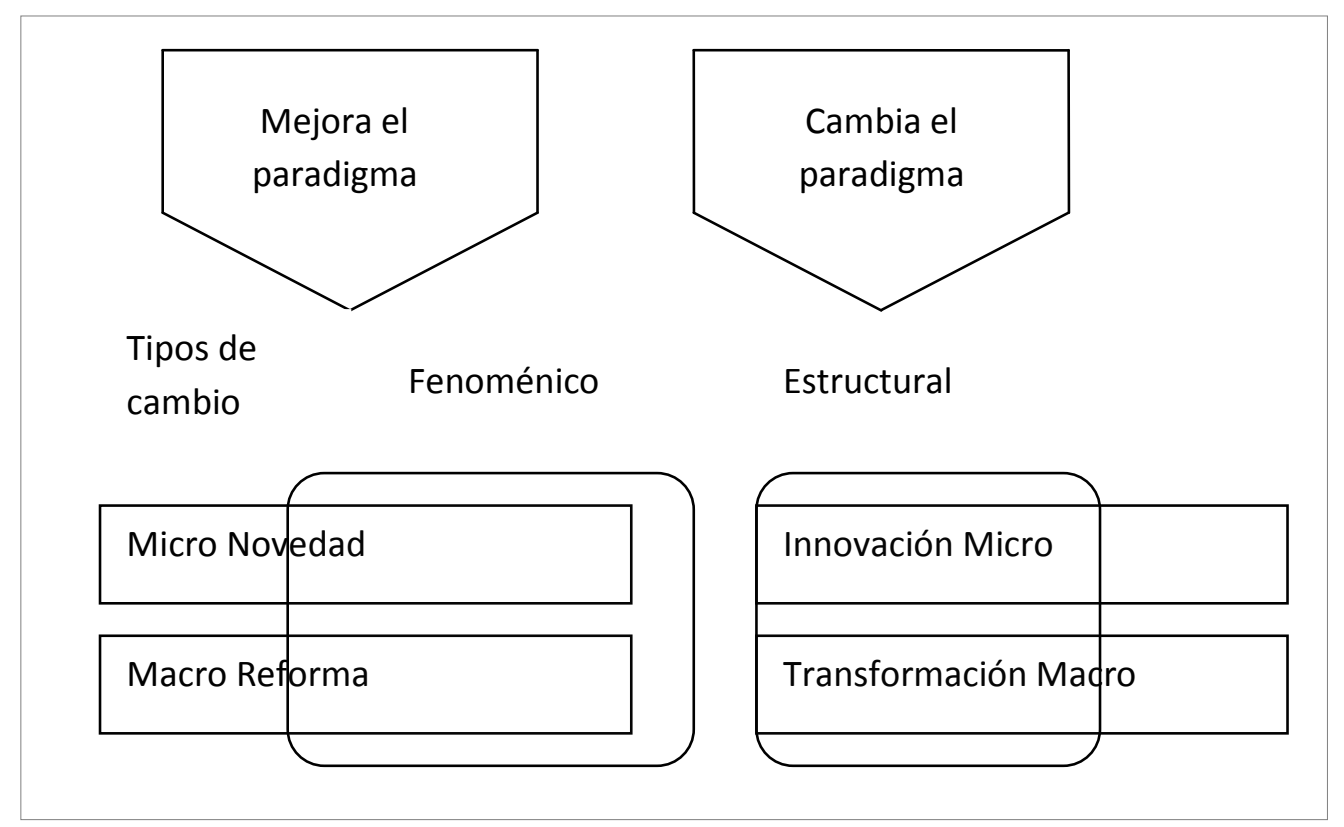

Fuente: Aguerrondo, en Gvirtz, S. \& Podestá, 2007.

Cuando se realizan cambios se indaga si se trata de: ¿mejorar el paradigma?, ¿cambiar el paradigma?, o si de lo que trata de es de: ¿un cambio fenoménico?, ¿un cambio estructural?, ¿una novedad?, ¿una innovación?, ¿una reforma?, o ¿una transformación? Los desafíos de las innovaciones, no son solamente para dar respuesta a las exigencias externas, también deben influir en forma proactiva en los cambios sociales, económicos y culturales a nivel interno (UNESCO, 2011).

Los ámbitos de las innovaciones en educación son diversos, a manera de ejemplo se citan los siguientes:

1. Innovación educativa como política de Estado.

2. Innovación educativa en la dirección y gestión del sistema educativo y cada uno de sus niveles.

3. Innovación educativa en los currículos, planes y programas.

4. Innovación educativa en los procesos educativos.

5. Innovación educativa en el uso de tecnologías de la información y la comunicación, TIC, y diversificación de ambientes de aprendizaje.

6. Otros. 
Las innovaciones educativas son cruciales para anticipar respuestas a los problemas emergentes y ofrecer nuevas soluciones a los temas pendientes es un desafío para avanzar hacia una educación de calidad que sea incluyente.

Tabla 4. Innovación educativa indicadores

\begin{tabular}{|c|c|}
\hline CONCEPTO & INDICADORES \\
\hline $\begin{array}{l}\text { La innovación se da porque "algunos elementos permiten pegar el } \\
\text { salto de paradigma. Y esto sólo lo puedo hacer con un cambio de } \\
\text { organización, en tres instancias: a nivel del aula, a nivel de la } \\
\text { institución de enseñanza y a nivel del sistema educativo" } \\
\text { (Aguerrondo, 2007, p.102). } \\
\text { En relación con este concepto la innovación es el resultado de un } \\
\text { proyecto de investigación en educación que busca un cambio de } \\
\text { paradigma a partir de la reorganización intencional y explicita de } \\
\text { relaciones, estructuras, contenidos y otros aspectos de orden } \\
\text { educativo. }\end{array}$ & $\begin{array}{l}\text { Proyecto que responda a una pregunta de un ámbito } \\
\text { teórico o práctico con impacto social apropiado para el } \\
\text { grupo humano y sus necesidades o expectativas. }\end{array}$ \\
\hline $\begin{array}{l}\text { La innovación educativa implica acciones vinculadas con } \\
\text { actitudes y procesos de investigación para la solución de } \\
\text { problemas que implican un cambio en la práctica educativa. }\end{array}$ & $\begin{array}{l}\text { Investigación educativa que corresponda a una producción } \\
\text { de conocimientos así como generación de experiencias } \\
\text { concretas relacionadas con cambios de actitudes positivas } \\
\text { y sus implicaciones en la práctica educativa. }\end{array}$ \\
\hline $\begin{array}{l}\text { Un modelo innovador identifica, valora, sistematiza, normaliza, } \\
\text { aplica y difunde el desarrollo de propuestas educativas válidas, } \\
\text { permite la transferencia a otras instituciones. } \\
\text { El modelo innovador puede implicar: negociación, manejo de } \\
\text { poder y conflicto. En este sentido ANUIES (2003) considera } \\
\text { pertinente la aplicación de teorías, procesos, métodos y técnicas } \\
\text { válidas, congruentes con las necesidades de la institución. }\end{array}$ & $\begin{array}{l}\text { La innovación debe mostrar el proceso de construcción de } \\
\text { sentido que valide las secuencias que se suceden en el } \\
\text { tiempo, según los períodos de aceleración, de vacío, de } \\
\text { reaceleración según los momentos, de temporalidad, } \\
\text { creando las condiciones permanentes, para que la } \\
\text { experiencia innovadora se convierta en una práctica } \\
\text { institucionalizada. }\end{array}$ \\
\hline $\begin{array}{l}\text { Un modelo innovador es una alternativa que articulada a la } \\
\text { calidad, mejorando la eficiencia, equidad y pertinencia... en los } \\
\text { procesos educativos. }\end{array}$ & $\begin{array}{l}\text { Concepto de calidad que da direccionalidad institucional; la } \\
\text { innovación es particular, teniendo en cuenta los criterios e } \\
\text { indicadores de calidad que se puede explicar por medio de } \\
\text { las relaciones entre sus elementos. }\end{array}$ \\
\hline
\end{tabular}

La propuesta del audiovisual y los productos de innovación en educación son vitales para complementar la discusión sobre otro tipo de producción científica en las llamadas ciencias blandas, que entidades como COLCIENCIAS deben empezar a tener en cuenta 
en sus procesos de medición de producción y para elaborar el modelo matemático que le permita valorar objetivamente los proyectos y la producción de la Investigación en ciencias de la Educación.

\section{MÉTODO, METODOLOGÍA Y TRABAJO DE CAMPO}

La información recabada en el trabajo de campo se obtuvo a partir de dos tipos de fuentes de información: la primera relacionada con entrevistas realizadas a personajes pertenecientes a los diferentes sectores que hacen parte del sistema de educación analizado; a saber: directivos, doctorandos, doctores egresados, docentes y administrativos. La segunda, mediante la aplicación de un cuestionario on-line, el cual fue elaborado utilizando la tecnología del software Google Docs y posteriormente enviado por correo electrónico a algunos doctorandos activos del Doctorado Interinstitucional en Educación de la Universidad Pedagógica Nacional.

El análisis se realizó teniendo en cuenta diferentes niveles de comparación: Primero, correspondiente al nivel de percepción, información general obtenida a través de la percepción de los doctorandos mediante el cuestionario; el otro se deriva de la información oficial institucional proporcionada por voces oficiales representantes de dicho doctorado. De igual manera, gracias a las dinámicas de la investigación, fue posible contar con otro nivel de comparación de tipo regional e internacional, ya que se contó con la colaboración de doctorandos de Programas Doctorales de otras regiones o departamentos, al igual que de otros países que también brindaron su opinión, información fundamental para elevar la discusión a otros escenarios.

El cuestionario fue constado por 18 doctorandos en un rango de edad de entre 37 a 53 años. De los 18 doctorandos indagados, 15 hacen parte activa del Doctorado Interinstitucional en Educación: Sede Bogotá - Universidad Pedagógica Nacional. Al indagar a los encuestados sobre las motivaciones para iniciar un programa doctoral, en general se apeló a las siguientes razones:

Motivaciones laborales y profesionales; necesidades de profundización en investigación; exigencias laborales e intereses profesionales. 
De igual manera, al indagar sobre los criterios de calidad que pensaban debía tener un programa doctoral, se destacaron las siguientes opiniones:

- Acreditación nacional e internacional.

- Convenios interinstitucionales.

- Gestión directiva.

- Liderazgo institucional con sus recursos para tener los mejores profesores y los mejores estudiantes.

- Inversión y recursos económicos.

- Estructura institucional.

- Disponibilidad de tiempo y horas para los asesores.

- Política institucional ligada a sus propósitos misionales, teniendo como prioridad la calidad de recursos económicos y talento humano.

- Calidad del currículo con coherencia con el contexto.

- Dar respuesta a los problemas de investigación de la educación.

- Movilidad internacional.

- Selección de personal docente con alta idoneidad para orientar los seminarios.

- Pertenencia de las temáticas, acordes a las líneas de investigación.

- Rigor académico y producción de conocimiento.

- Producción de investigación.

Estos criterios mencionados por los doctorandos guardan coherencia con los procedimientos de evaluación y acreditación de la calidad en los programas de Educación Superior: autoevaluación, evaluación externa e informe final; existencia de componentes de análisis comunes (filosofía, misión y visión institucional, plan de desarrollo institucional, estructura de gobierno, carreras, recursos humanos y financieros, servicios de atención estudiantil, recursos físicos, convenios de cooperación, comunicación y tecnología) (Videla, 2008). 
En cuanto a la percepción sobre la eficiencia y eficacia de los diferentes estamentos que hacen parte de la estructura institucional que apoyan a la Institución Universitaria que ofrece el Programa Doctoral en Educación (Estamento Directivo, Académico, Financiero, Administrativo y Centro de Investigación), se hace interesante analizar la percepción de los doctorandos en cuanto a eficiencia: este indicador recibió para los estamentos financiero y administrativo una calificación de percepción baja (Poco eficiente) y para los estamentos de centro de investigación y estamento académico reciben una mejor calificación, aunque no excelente. En cuanto a la eficacia, se destacan puntuaciones más positivas para la mayoría de los estamentos. Como eficaz fueron puntuados los estamentos directivo (65\%), académico (76\%), administrativo (53\%), centro de investigación - eficaz (41\%), muy eficaz (6\%). En tanto que el estamento financiero recibió una baja calificación "Poco eficaz" con un promedio de 65\%.

Puede decirse que los estamentos que merecen una mejor calificación en términos de eficiencia y eficacia corresponden al académico y el centro de investigación, mientras que los de peor percepción han sido los estamentos financiero y administrativo. De alguna manera, los doctorandos tienen una buena percepción por lo que se hace al interior del doctorado con relación a los aspectos académicos y curriculares, sin embargo critican fuertemente la organización institucional para apoyar y potenciar los esfuerzos que se realizan al interior del doctorado.

\section{Endogamia del doctorado}

Al indagar a la muestra de los doctorandos sobre la procedencia de los estudiantes del Programa de Doctorado, se formularon las siguientes opciones: Propia institución (Universidad Pedagógica Nacional) con un resultado de (88\%), otra institución del mismo país con un (94\%), de la región de América Latina con un (12\%) y de todas partes del mundo (0\%). Se encontró resultados impactantes que reflejan la desconexión casi que total del programa académico con doctorandos de origen internacional que permitan abrir las discusiones académicas y orientarlas a las problemáticas de los contextos regionales. 


\section{Gráfico 9. Procedencia de los estudiantes del programa}

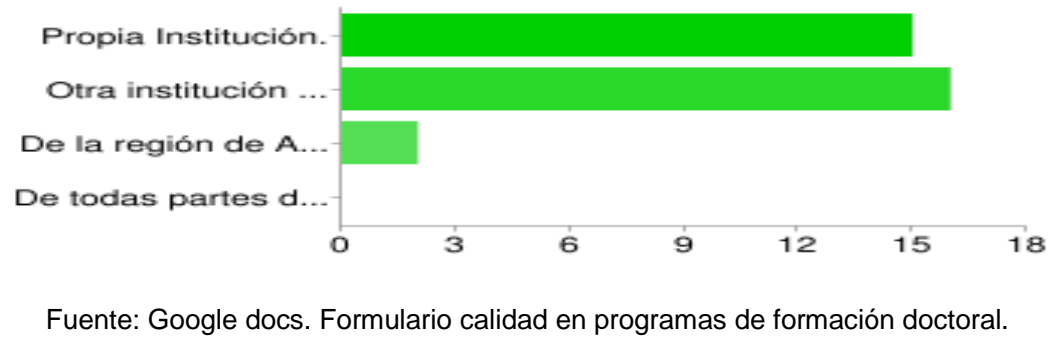

Nota: Los usuarios pueden seleccionar más de una casilla de verificación, por lo que los porcentajes pueden superar el $100 \%$.

De igual manera, de forma generalizada los doctorandos participantes de la investigación manifiestan directamente que existe una alta proporción de doctorandos matriculados con relación a la capacidad docente ofrecida por la institución para las actividades de asesoría. De esta manera explican que no hay la suficiente cantidad de docentes para acompañar con calidad los procesos investigativos desarrollados por los doctorandos. Con igual rigurosidad se abordan los procesos de evaluación y selección de aspirantes en términos de requisitos de ingreso, para este ítem los doctorandos expresaron en general que los criterios de selección de aspirantes no son rigurosos. Las universidades intentan tener una cohorte estándar y debido al bajo número de inscritos no se permiten rechazar postulaciones, lo cual incidiría en un bajo número de estudiantes inscritos. Las Universidades quieren cohortes grandes.

\section{Competencias en segunda lengua}

En cuanto a la exigencia del segundo idioma se pudo percibir que las Universidades limitan a los postulantes a los exámenes internos de los institutos o departamentos de idiomas de la misma universidad, pero no exigen niveles de inglés de acuerdo con los estándares internacional relacionados con los exámenes o test como el TOEFL, Michigan, Oxford, entre otros, que además de medir el nivel de inglés de los aspirantes, facilita la homologación, participación o inscripción a programas posgraduales de otros países. De igual manera, se critica los exámenes internos para conocer el nivel y dominio de una 
lengua extranjera realizados por el Programa Doctoral, pues destacan que los criterios por los que más se indagan este tipo de exámenes son gramática, escucha, lectura y escritura; sin embargo, no se analiza de manera profunda si efectivamente el aspirante tiene competencias conversacionales, de pronunciación y de comprensión de lectura en los contexto académicos en los que se desarrollará el doctorado. Lo anterior, teniendo en cuenta que el doctorando debe tener competencias para 1) Acceder a fuentes bibliográficas y a páginas institucionales en una segunda lengua; 2) Exposición y presentación en ponencias internacionales; 4) Establecer contactos con investigadores de otras latitudes para el fomento, mantenimiento y consolidación de trabajo colaborativo y en red; 5) la redacción y lectura de artículos científicos en segunda lengua, entre otros.

Por otro lado, se criticó fuertemente la posibilidad de tener una dedicación de tiempo completo para la realización del doctorado, ya que muchos expresaron que obligaciones de tipo laborales y familiares impiden dedicarse por completo al estudio y reflexión obligada de este proceso de formación. Se pudo establecer que los doctorandos tienen en promedio una dedicación de entre dos y tres horas diarias, casi siempre en la noche, luego de una larga jornada laboral, para dedicarse al estudio del Doctorado. Esta imposibilidad de dedicación completa al doctorado se encuentra muy relacionada con los pocos incentivos económicos para con los doctorandos, aspecto sobre el que se profundizará más adelante.

Para el Doctor egresado², del Doctorado Interinstitucional de Educación, sede Bogotá Universidad Pedagógica Nacional,

Lo que más se requiere para hacer el doctorado es tiempo, es más valioso el tiempo que incluso el problema económico de la financiación [...] Digamos en el caso de nosotros lo que más pedíamos era tiempo, porque la universidad donde trabajábamos nos descargaba de horas y actividades; pero de todas maneras así se descargue a uno medio tiempo, todavía queda con responsabilidades en 20 horas en que uno tiene que dictar 8 horas de clase como mínimo, tiene que asistir a reuniones de profesores, tiene que cumplir una serie de compromisos que de todas maneras quitan 203 días a la semana hábiles [...].

\footnotetext{
${ }^{2}$ Se reserva el nombre del Doctor egresado del Doctorado Interinstitucional de Educación, sede Bogotá Universidad Pedagógica Nacional por solicitud del mismo.
} 


\section{Egresados}

Un $76 \%$ de los encuestados calificó negativamente el seguimiento de la Universidad a la trayectoria laboral y académica de los egresados. Puede manifestarse que luego de la obtención del título hay un alejamiento radical de la institución universitaria, se carece casi que completamente de programas de seguimiento a egresados que permitan dar cuenta a la institución de la situación laboral real de los éstos, niveles de ofertas salariales, los problemas del contexto con respecto a las competencias formadas en los doctorandos.

\section{Aspecto curricular y líneas de investigación}

Los entrevistados manifestaron que si bien hay un trabajo esforzado por parte del equipo directivo y profesoral por estructurar una malla curricular rigurosa, actual y pertinente al contexto nacional; las líneas de investigación no responden directamente a una política institucional de investigación. Expresan que hay mucha improvisación en cuanto al manejo y aprovechamiento de la producción de investigación del doctorado, pues no se influye, tal como debería serlo, en el planteamiento de maestrías u otros programas de formación pos gradual a partir de los adelantos del programa doctoral. Se esperaría que el doctorado orientara los lineamientos en investigación de otros programas afines en área de conocimiento, sin embargo se percibe un distanciamiento entre los objetivos internos del programa doctoral y los deseos institucionales y de otros programas de posdoctorado.

Los niveles de pregrado y posgrado se deben articular desde la docencia, la investigación y proyección social y no se ha logrado, falta gestionar el programa [...] La propuesta curricular del doctorado se ajusta a las líneas de investigación de sus docentes, pero no depende del pregrado y la maestría [...] Las líneas de investigación se deben consolidar del pregrado al doctorado para que sus propuestas curriculares generen impacto; hasta ahora no se ha dado [...]-La producción investigativa debe dar solución a los problemas educativos para mayor consolidación de pregrado a doctorado para generar impacto positivo [...] Se pierden los trabajos por falta de articulación y procesos individuales aislados 
de las verdaderas necesidades educativas y sociales del contexto $[\ldots]$

(Fragmento de entrevista realizada).

Es interesante la percepción de los encuestados sobre el impacto social de las actividades y producción investigativa generada en el doctorado, pues la mayoría de los ítems recibe una calificación mediana. La escala de medición se formuló con los siguientes rangos (Nulos, malos, regular, bueno y excelente). El ítem Servicios a la sociedad: Asesorías, consultorías, interventorías, asistencia técnica, proyectos de intervención, etc., obtuvo un porcentaje de 71\%; igual que el ítem Gestión social: Programas y proyectos de desarrollo social y comunitario, con un 71\%; Egresados: Relación y participación en la vida universitaria, participación en consultorías y/o asesorías, el cual presenta un resultado de 65\%; Comunicación del quehacer académico: Generación de opinión pública, un 71\%; Transformaciones en la comunidad: Vinculación a planes de desarrollo local, organización comunitaria o intervención social, un 65\% presentan mayoritariamente calificación de regular. Si bien los doctorandos no expresan que estos aspectos sean inexistentes y del todo malos, si se presenta una fuerte orientación a que existen pero insuficiente, con muchos aspectos a mejorar; de tal forma que no se puede decir que el impacto social del programa de doctorado sea excelente, ni siquiera bueno, de acuerdo con los aspectos analizados.

Vale resaltar que los ítems con calificación más desfavorable se relacionan estrictamente con el impacto del currículo y la producción de investigación en el contexto social y comunitario alrededor del programa.

El único ítem que tuvo una calificación repartida entre regular y bueno fue el que indagaba por Aportes al sistema educativo: Participación en el desarrollo de políticas educativas e incidencia en los diferentes niveles educativos que se repartieron en un $6 \%$ hacia el malo, un $35 \%$ hacia el regular y un $29 \%$ hacia el bueno.

\section{Calificación docente}

Teniendo en cuenta los criterios iniciales, se indagó a los encuestados sobre la calidad docente a nivel general, sin apelar a que se calificara a docentes específicos. La 
percepción de los doctorandos sobre la calidad de los docentes no es más positiva que en los aspectos valorados anteriormente.

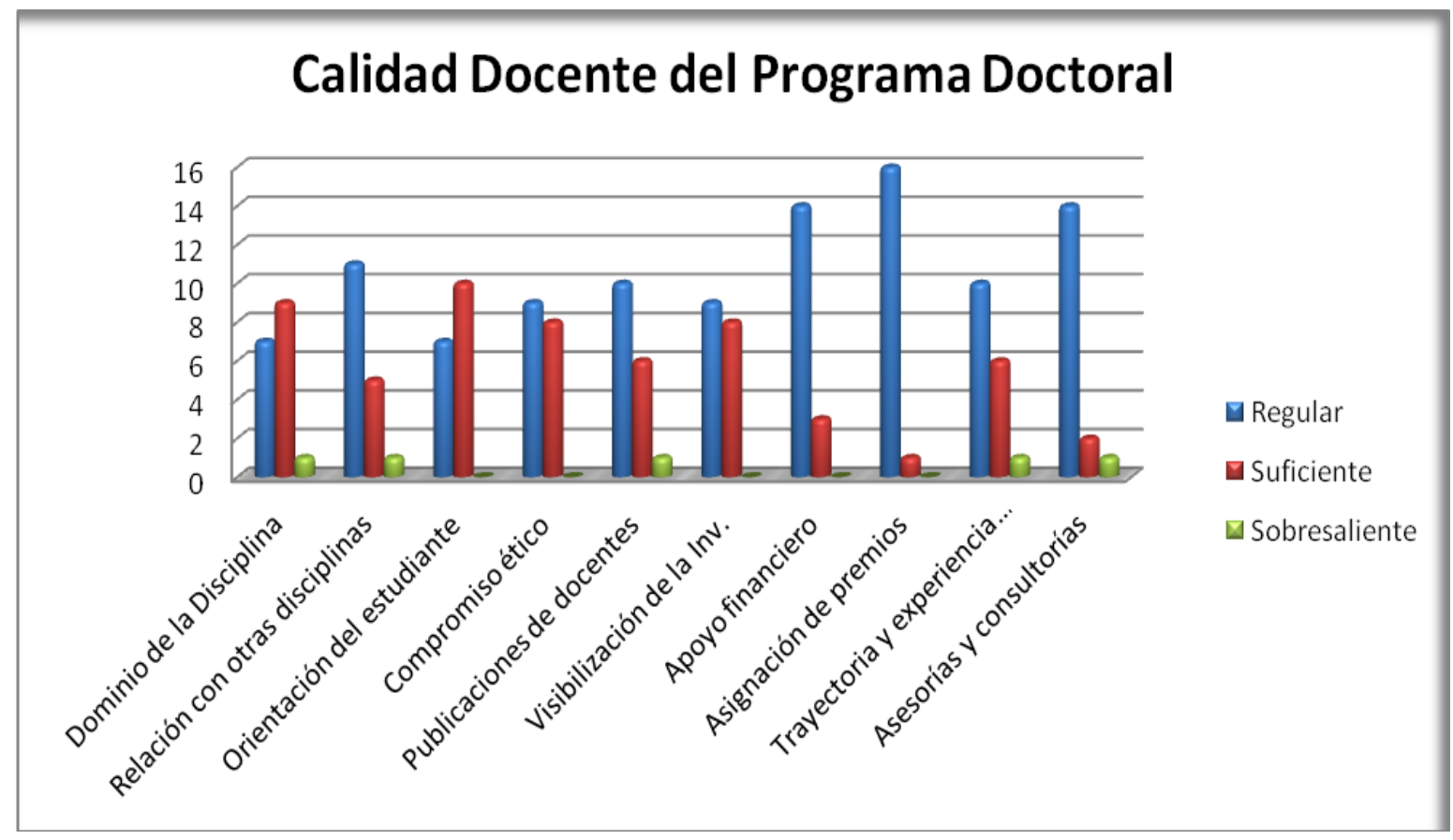

Los aspectos que recibieron una calificación positiva, aunque no de manera mayoritaria, fueron Dominio de la disciplina: con un porcentaje de 50\% y Orientación del estudiante de $61 \%$. Lo cual refleja que los doctorandos reconocen a sus docentes como conocedores expertos de ciertos temas, que se esfuerzan por dar un buen acompañamiento en el proceso de asesorías, lo anterior se puede establecer por otra de las preguntas que apelaba por el Compromiso ético de los docentes, la cual obtuvo una calificación intermedia regular de $50 \%$ y suficiente $45 \%$; lo que por su inclinada tensión hacia los dos lados, se determinó que las respuestas apuntan directamente a experiencias personales de los doctorandos ya que no marcan una tendencia clara hacia una de las opciones.

Sin embargo, los doctorandos son muy críticos en los ítems referidos a Relación de la disciplina con otras esferas de conocimiento: se calificó el ítem Los docentes promueven y amplían los intereses del doctorando y establecen relaciones de su disciplina con las tesis de los doctorandos con una tendencia hacia el regular con un $61 \%$, al igual que el ítem Participación en asesorías y consultorías con un 78\% en lo regular, pero en la calificación se contraría al ítem Asignación de premios, galardones o condecoraciones internas o externas, con una valoración regular de un $89 \%$, Apoyo financiero con un regular $78 \%$. En 
general el ítem de publicaciones docentes Revistas indexadas, libros, capítulos de libros, coediciones, etc., recibe un mediano de 56\%. En tanto que el ítem Visibilización de la investigación: ponencias y participación en eventos científicos se calificó de manera media con un $50 \%$, y finalmente Trayectoria y experiencia práctica tuvo un regular $56 \%$.

En algunos casos se constató una tendencia marcada por dos opciones opuestas, lo cual puede deberse a que existen acciones positivas que se han presentado: publicaciones de docentes, premios, ponencias, pero estas actividades no corresponden a una política institucional coherente de la que todos los estudiantes tengan opción de participación, corresponden más a experiencias afortunadas pero aisladas.

Para el Doctor egresado ${ }^{3}$ del Doctorado Interinstitucional de Educación en este programa la calidad profesoral es relativa y algo improvisada:

Un doctorado lo hace el mismo estudiante [...] evidentemente influyen mucho los profesores, el tutor y el director de tesis, pero digamos que el nivel de exigencia se lo imprime uno mismo [...] uno puede llegar a tener muy buenos profesores, excelentes, pero si no satisfacen las expectativas de uno pues eso se pierde o si uno no tiene las herramientas o las competencias necesarias para aprovechar esos profesores también se pierden. Hay profesores de primera categoría, de segunda y de tercera, hasta los pésimos y hasta los colados, en la academia pasa eso de que tú me llamas yo te llamo, tú me ayudas yo te ayudo, un profesor va a México por decir algo, que fue lo que paso con un pésimo profesor que tuvimos, yo te invito tu me invitas, yo te invito a México y tú me invitas a Colombia, yo te invito a Buenos Aires tu me invitas a Medellín, [...] se puede colar gente muy mala. [...] Malo puede decir varias cosas, no malo que sea incompetente no necesariamente, malo puede ser para uno un profesor que esta desactualizado y que sólo se ocupa de una temática especifica y que es intolerante a otras discusiones [...] o lo contrario hay profesores excelentes, brillantísimos que tienen un reconocimiento internacional pero que los traen por su fama y figura de renombre y finalmente resulta que no tiene nada que ver con los proyectos de los estudiantes que tomaron ese seminario a pesar de que el seminario llevaba ese título (Fragmento entrevista realizada).

\footnotetext{
${ }^{3}$ Se reserva el nombre del Doctor egresado del Doctorado Interinstitucional de Educación, sede Bogotá Universidad Pedagógica Nacional por solicitud del mismo.
} 


\section{Gestión}

De igual manera, en otro aparte del cuestionario, se solicitó a los doctorandos que calificaran la gestión del Programa Doctoral teniendo en cuenta los siguientes procesos:
C1 Se contempla financiación para participación en eventos científicos
C2 Se visualiza calidad en la infraestructura investigativa con estándares internacionales: Biblioteca, acceso a bases de datos, software, suscripción a revistas, excelente conectividad y tecnología.

C3 Se fomenta la participación activa en Redes de Conocimiento Nacionales y/o Internacionales.

C4 Se publican los productos de investigación de los doctorandos: Libros, capítulos de libros, revistas indexadas, etc

C5 Publicaciones internas del Programa Doctoral

C6 Se conceden becas, medias becas 0 apoyo para gastos de matricula

C7 Se conceden becas, medias becas 0 apoyo para gastos de Sustento.

C8 Se conceden becas, medias becas o apoyo para gastos de Investigación.
C9 Se financian las Investigaciones de los doctorandos: Convocatorias Internas.

C10 Se manejan relaciones interinstitucionales para financiación de proyectos de los doctorandos.

C11 Se ofrecen oportunidades de intercambios académicos de docentes con otras instituciones

C12 Se promueven oportunidades de intercambios académicos de Doctorandos con otras

C13 instituciones.

C14 Se ofertan posibilidades de pasantías relacionadas con la tesis del doctorando.

C15 Invitación de investigadores externos

C16 Se contemplan oportunidades de publicaciones por coedición

C17 Vinculación de doctorandos a los Grupos de Investigación del Programa de Doctorado. 
C18 Se gestionan servicios de asesoría y consultorías externas en los que participen los doctorandos
C19 Convenios y alianzas que potencien la investigación interdisciplinar e interinstitucional

\section{Gráfico 10. Procesos de Gestión}

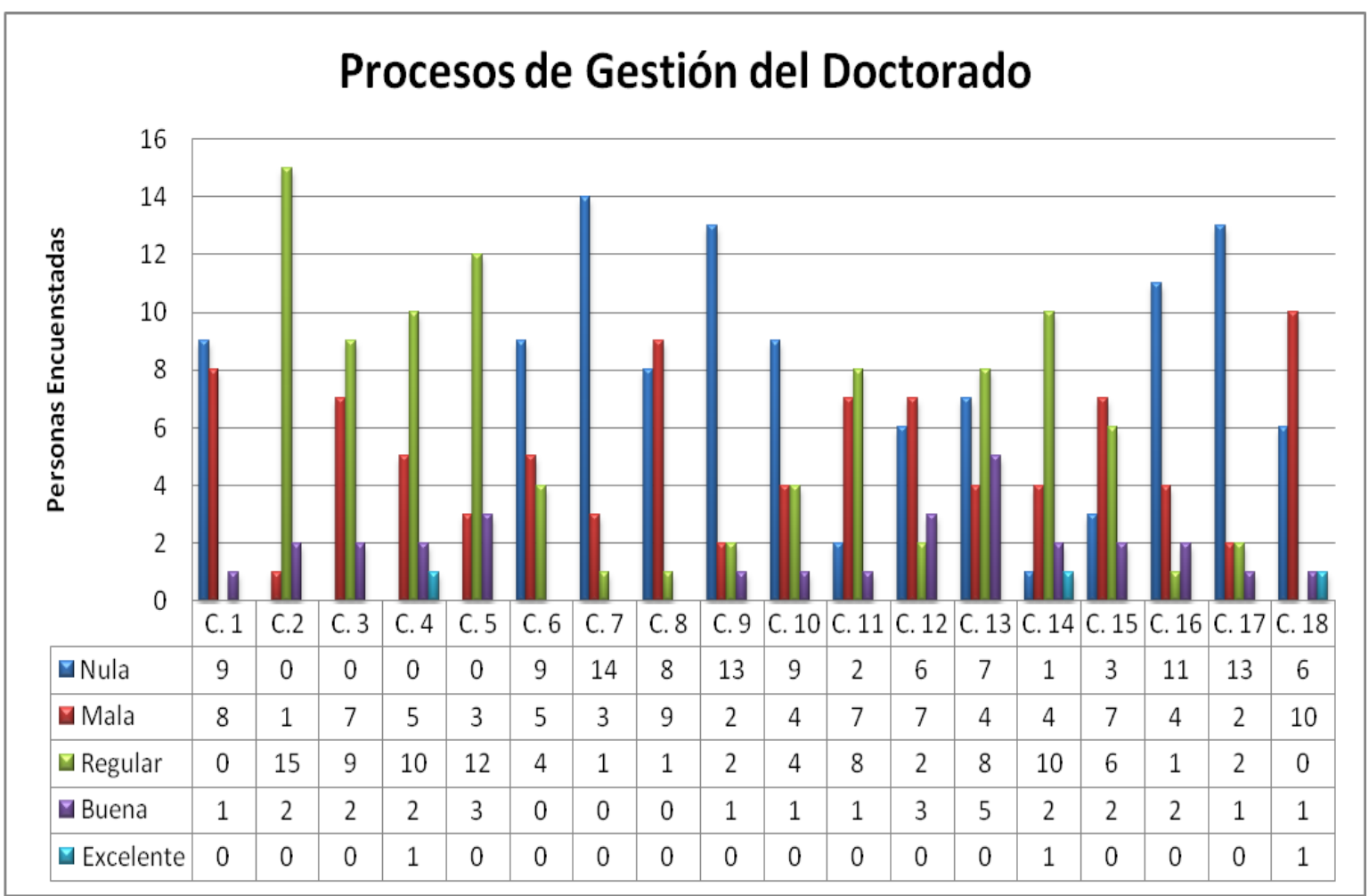

Fuente: Elaboración Propia

Antes de entrar al análisis de los resultados expuestos por el cuadro anterior, es interesante detenerse en lo gráfico del mismo y destacar que en casi todas las categorías indagadas las barras azules, correspondientes al rango nulo, roja, al rango malo, y verde olivo, correspondiente a regular, son las más altas en este cuadro de medición de percepciones. En tanto que la barra azul clara, correspondiente al rango excelente, casi nunca se presenta en el mismo. Se destaca que la percepción general de los doctorandos acerca de los procesos de gestión realizados al interior del mismo no es muy satisfactoria.

Entrando al análisis, puede decirse que los aspectos calificados como nulos por los doctorandos corresponden a: 
C1. Se contempla financiación para participación en eventos científicos.

C6. Se conceden becas, medias becas o apoyo para gastos de matrícula.

C7. Se conceden becas, medias becas o apoyo para gastos de Sustento.

C9. Se financian las Investigaciones de los doctorandos: Convocatorias Internas.

C10.Se manejan relaciones interinstitucionales para financiación de proyectos de los doctorandos.

C16. Vinculación de doctorandos a los Grupos de Investigación del Programa de Doctorado.

C17. Se gestionan servicios de asesoría y consultorías externas en los que participen los doctorandos.

Al tiempo que los calificados como malos fueron:

C8. Se conceden becas, medias becas o apoyo para gastos de Investigación.

C18. Convenios y alianzas que potencien la investigación interdisciplinar e interinstitucional.

Tales resultados resaltan debilidades del programa doctoral en estrategias de financiación, falta de vínculo con los grupos de investigación y acciones de asesoría. Sobre estos aspectos la Doctora Rosalba Pulido, Directora del Programa afirma:

Tenemos básicamente como fuente de investigación recursos propios de la institución en algunos casos financiación de COLCIENCIAS, en otros casos recibimos apoyo de organismos gubernamentales y no gubernamentales para alguna investigación específica. Igualmente estamos enfocados en conseguir apoyo de cooperación internacional. Pero el estudiante no tiene, por parte del programa doctorado, financiación para hacer su investigación porque no tenemos manera.

Sobre el tema, igualmente el doctor egresado del programa expresó:

Hay convenios pero apoyo económico no lo hay; y creo que en ningún doctorado en Colombia lo haya, es igual que en maestría es muy difícil. Aunque si hay convenios y algunos que logran apoyo financiero en COLCIENCIAS [...] o apoyo financiero por la misma universidad, lo cual es muy difícil o apoyo financiero por entidades internacionales; pero, primero es bien difícil obtener 
ese apoyo económico y financiero, y segundo, queda uno muy lastrado muy cargado de deudas y no sólo de deudas económicas sino de deudas académicas de compromisos.

De igual manera preocupa la calificación regular que los doctorando atribuyen a aspectos como:

C2. Se visualiza calidad en la infraestructura investigativa con estándares internacionales: Biblioteca, acceso a bases de datos, software, suscripción a revistas, excelente conectividad y tecnología.

C3. Se fomenta la participación activa en Redes de Conocimiento Nacionales y/o Internacionales.

C4. Se publican los productos de investigación de los doctorandos: Libros, capítulos de libros, revistas indexadas, etc.

C5. Publicaciones internas del Programa Doctoral.

C14. Invitación de investigadores externos.

Sobre todo porque estos se relacionan con la visibilización e impacto de las producciones investigativas de los doctorandos. El Doctor egresado expresa:

La publicación en este doctorado interinstitucional es un gran problema, porque las tres universidades tienen muy pocas revistas indexadas para publicar los trabajos de los estudiantes, entonces le toca salir a la gente a buscar en otras universidades con revistas indexadas; con el agravante, por una lado, que ahora las revistas cobran por recibir el artículo y, por otro, que hay una larga fila de gente esperando a que se publiquen sus artículos, entonces se vuelve un circulo vicioso, porque un requisito es que usted tiene que publicar en revista indexada pero usted envía su artículo y le toca esperar un año [...] En el doctorado que yo hice ese fue uno de los mayores problemas que había, uno de los requisitos que teníamos era escribir tres artículos publicables en revistas indexadas, era terrible porque uno envía el artículo al doctorado, este busca unos evaluadores, en ese proceso de buscar los evaluadores, hacerles llegar el artículo, que lo evalúen y lo vuelvan al doctorado se gasta unos 6 o 8 meses (sin contar con los procesos de peritaje de la revista) cumpliendo un requisito podía gastarse uno 2 años, desde el momento en que uno lo cumplía, antes leer e investigar y después enviarlo, incluso tengo compañeros que empezaron conmigo y no se han podido graduar porque se les alargo el tiempo, hubo 
evaluadores que nunca entregaron el concepto del articulo y les tocó buscar otro y eso se le sale a uno de las manos. Eso yo creo que es una de las mayores dificultades que tienen los doctorados en Colombia, los requisitos que le ponen a uno a publicar artículos en revistas indexadas cuando hay muy pocas y esas revistas ya tienen unos autores de base, que aunque no son de base y si un estudiante de doctorado envía un articulo a una revista $X$ de tal universidad indexada y a esa revista le pidieron a una de las figuras de la academia colombiana, obviamente salen los artículos que no son de ellos, lo otro y lo digo con conocimiento de causa porque yo soy evaluador de artículos de revistas, estoy en la base de datos de las principales revistas de educación y los artículos que me han pasado son muy malos, yo rechazo un $70 \%$ de los artículos que leo por considerar que no tienen la suficiente calidad para ser publicados en una revista indexada de alto nivel científico, son trabajos que repiten o reproducen una teoría o una experiencia no aportan gran cosa a la discusión académica y a la investigación propiamente dicha, artículos de tan bajo nivel en los doctorados es otro problema, incluso artículos donde se ven profundas dificultades de escritura, de redacción, eso de entrada lo sesga a uno porque si uno lee el articulo de un estudiante y encuentra errores de ortografía, de redacción, de puntuación, ese tipo de cosas lo pone en entredicho.

Por su parte la doctora Rosalba Pulido, Directora del programa expone que se trabaja por fortalecer el Programa:

Tenemos un sello característico, le apostamos a la autonomía del estudiante, asumimos que el estudiante llega como una persona que está en franca asesoría con su asesor de tesis, el estudiante se inscribe al programa con un proyecto de investigación que tiene que estar en capacidad de articular a alguno de los grupos de investigación de un énfasis particular, lo ideal es que el estudiante tenga contacto previo con la persona que pueda dirigir su tesis, que se miren los lineamentos gruesos del proyecto y ahí se presenta.

\section{CONCLUSIONES}

La calidad de un Programa de formación doctoral depende de la sincronía entre diferentes partes del sistema educativo del que éste hace parte: directivos, administrativos, 
estudiantes, docente, Política institucional y políticas nacionales y globales para el desarrollo de la ciencia y el conocimiento. De acuerdo con la definición de calidad del CNA cada institución define para sí un sentido y razón de ser y con respecto a este se estructuran los estándares de calidad a medirse. A pesar del contexto situacional en el que los doctorados se desenvuelven, se debe destacar que hay un esfuerzo institucional, nacional e internacional por desarrollar procesos de evaluación y acreditación que vigilen, estimulen y certifiquen la calidad de los Programas en los diferentes países de América Latina. Prueba de esto es la conformación de la Red Iberoamericana para la Evaluación y la Acreditación de la Calidad de la Educación Superior.

Las acciones y estrategias en tanto gestión directiva, administrativa, financiera, curricular y pedagógica y del Comité Asesor o Científico del Programa del Doctorado Interinstitucional en Educación deben fortalecerse en los aspectos relacionados con el impacto social del conocimiento desarrollado al interior de éste. Se deben aunar esfuerzos para lograr un mayor impacto social, académico y científico, acorde a las necesidades locales y regionales, así mismo deben ofrecer soluciones concretas a las problemáticas del país y nuevos planteamientos desde los cuales pensar la educación para construir una sociedad más humana y equitativa. Resaltando que el conocimiento del aula de clase debe trascender al contexto real para obtener allí una retroalimentación, con el propósito de ser llevado nuevamente a la Institución para reevaluarlo y generar nuevas propuestas y conocimiento.

La formación en el Programa tendrá que implementar sistemas de gestión y cambios en los estilos de liderazgo construidos a partir de procesos de participación y reflexión permanente, si quiere cumplir con su objetivo de formar actores educativos al servicio de la nación y del mundo, comprometidos con la transformación de la educación y la construcción de futuro.

Hablar de cambios en los estilos de liderazgo requiere hacer un diagnóstico de la situación actual del doctorado en educación de la UPN, para poder definir líneas de acción que direccionen los cambios que se consideren necesarios. Se debe conocer a profundidad el contexto de la institución en cuanto a problemáticas, necesidades y aciertos, para visionar metas concretas y ajustar la planeación e implementación de las mejoras. 
El trabajo directivo necesita encaminarse hacia el conocimiento del Programa Doctoral para desarrollar sus habilidades administrativas, teniendo como meta la búsqueda permanente de la calidad del conocimiento y la manera en la que se expresa esa realidad social-institucional al responder a las necesidades mundiales de trabajo y producción. Un sistema es de calidad si cumple con su función de ayudar a la integración social.

Dentro del proceso de Gestión Directiva es definitivo desarrollar un estilo de liderazgo que permita a todos los miembros de la comunidad educativa hacer parte de las diferentes acciones que se desarrollan.

Los Doctorados en educación que existen en Colombia no están respondiendo a las problemáticas educativas relevantes de los diferentes niveles educativos de nuestro país, por ello se hace necesario promover Programas que sean más competitivos a nivel nacional e internacional.

Al hablar de Doctorados en Colombia debemos reconocer que la inversión estatal es muy baja en comparación con los estándares internacionales, además los recursos técnicos carecen de elementos básicos para su desarrollo y de estímulos económicos y profesionales. Es muy importante definir parámetros claros de calidad que les permitan a los aspirantes a Doctores distinguir entre aquellos posgrados apenas aprobados, los que tienen un alto nivel, los que son de excelencia y aquellos que aspiran a tener un reconocimiento internacional.

Si se quiere desarrollar investigación de calidad mundial es indispensable desarrollar Programas de doctorado en todas las universidades del mundo. El desarrollo de estos Programas es un paso necesario en la consolidación de capacidades para desarrollar la investigación y producir conocimientos de punta.

La educación superior solo podrá mejorar su calidad si existe una actitud de continua innovación en sus modelos de gestión.

Tras la promesa de progreso y desarrollo social, tecnológico, económico y productivo; la formación en y producción de investigación es una de las metas más importantes que gobiernos, empresas, instituciones educativas y la sociedad latinoamericana en particular se imponen en la actualidad. 
A pesar del contexto situacional en el que los posgrados se desenvuelven, se debe destacar que hay un esfuerzo nacional e internacional por desarrollar procesos de evaluación y acreditación que vigilen, estimulen y certifiquen la calidad en las de los programas en los diferentes países de América Latina. Prueba de esto es la conformación de la Red Iberoamericana para la Evaluación y la Acreditación de la Calidad de la Educación Superior.

El presente documento es específicamente descriptivo en cuanto a su propuesta, pero necesitaría de un desarrollo investigativo a nivel de maestría para complementar los aspectos operaciones en términos de las ecuaciones del software que permita categorizar y mediar los diferentes lineamientos que permitan valorar y atribuir un peso en términos significativos a los proyectos de investigación que se desarrollen en el campo de la investigación en el área de educación

\section{REFERENCIAS}

Borja, B. (2003). La gestión Educativa al servicio de la innovación. Formación pedagógica. Venezuela: Fundación Santa María.

Gimeno, J. (2010). Saberes e incertidumbres sobre el currículum. Madrid: Ediciones Morata.

González V. H. (1994). Las innovaciones: Un punto de partida, no un punto de llegada. En: Desde La Otra Orilla. Itinerario de una innovación. Santa Fe de Bogotá: Consejería Presidencial para los Derechos Humanos.

Gore, E. (2004). La Educación En La Empresa. Buenos Aires: Ediciones Granica S.A.

Gvirtz, S. \& Podestá, M. E. (Eds.). (2007). Mejorar la gestión directiva en la escuela. Buenos Aires : Ediciones Granica S. A.

Harris, A. y Chapman, C (2002) Democratic leadership for school improvement in challenging contexts. Copenhagen: Comunicación presentada en el Internacional Congress on School Effectiveness and Improvement.

Oppenheimer, A. (2011). ¡Basta de historias!. Bogotá: Random House Mondadori, S.A. 
Romero, C. (2004). La escuela media en la sociedad del conocimiento. Buenos Aires: Ed. Novedades Educativa

Mintzberg, H. (1984) La naturaleza del trabajo directivo, Ariel.

Stoner, J. (1996) Administración (6 a a ed.) México: Prentice - Hall Hispanoamericana, S.A.

Valles, M. (2000). Técnicas cualitativas de investigación social. Madrid. Editorial Síntesis. Segunda Edición.

Vásquez R., F. (2007) Educar con Maestría. . Bogotá. Ediciones La Salle

Páginas Web

Alfonzo. (2008) Innovación Educativa. Revisado el 20 de agosto de 2011. http://www.natureduca.com/blog/?p=237.

Anuies (2003), Innovación Educativa, México Blanco R. Y Messina G. (2000), Estado del arte sobre las innovaciones educativas en América Latina, Bogotá, Colombia, Convenio Andrés Bello. Recuperado de: www.natureduca.com/blog/?p=237

Blanco R. y Messina (2000) Estado del arte sobre las innovaciones educativas en América Latina, Bogotá, Colombia, Convenio Andrés Bello. Visto julio de

2011.www.natureduca.com/blog/?p=237

CNA. (2008) Situación actual de los doctorados en Colombia: análisis de indicadores que tipifican características importantes. Bogotá. Recuperado de: cmsstatic.colombiaaprende.edu.co/.../articles-186363_SitDoc_Ind.p.

CNA. (2009) "Lineamientos para la creación de alta calidad de Programas de Maestrías y Doctorados" Bogotá. Recuperado de: www.cna.gov.co/.../articles186363_archivo_pdf_lineamientos_MyD.

Cruz C. (2005) 1 Breve descripción de los procesos de evaluación y acreditación. Recuperado de: www.salvador.edu.ar/publicaciones/evaluaccion/11/videla. 
Observatorio Colombiano de ciencia y Tecnología OCyT (2010) Indicadores de ciencia y Tecnología Colombia. Recuperado de: www.ocyt.org.co/.../index.php?...95\%3Aindicdoresde-ciencia-y-tec.

Secretaría de Educación Básica de México. (2009). Modelo de Gestión Educativa Estratégica Programa escuelas de calidad Dirección General de Desarrollo de la Gestión e Innovación Educativa. Recuperado de: http://www.edomex.gob.mx/ecal/doc/pdf/MGEE.

UNESCO (2000) Gestión educativa estratégica, IIPE Buenos Aires. Recuperado de: http://www.lie.upn.mx/docs/DiplomadoPEC/Pozner_M2.

UNESCO (2009) Conferencia Mundial sobre la Educación Superior. (París). Recuperado de http://unesdoc.unesco.org/images/0011/001163/116345s.

VIDELA, MARÍA LAURA. (2008) Breve descripción de los procesos de evaluación y acreditación en América Latina. Recuperado de:

www.salvador.edu.ar/publicaciones/evaluaccion/11/videla.

Revistas

Almaguer, T. (2000), La calidad en la educación pública en México. Revista Ege. Escuela de Graduados en Educación, publicación bimestral, año 1, núm. 3, noviembre-diciembre Universidad Virtual.

Federación Internacional Fe y Alegría (2010). Programa Calidad de la Educación. Revista No. 5 Septiembre, Ladiprint Editorial S.A.S.

Posgrados (2010 - 2011). Edit. Legis 